\title{
Myosin 1g Contributes to CD44 Adhesion Protein and Lipid Rafts Recycling and Controls CD44 Capping and Cell Migration in B Lymphocytes
}

\section{Orestes López-Ortega and Leopoldo Santos-Argumedo*}

Departamento de Biomedicina Molecular, Centro de Investigación y de Estudios Avanzados del Instituto Politécnico Nacional, Ciudad de México, México

OPEN ACCESS

Edited by:

Michael R. Gold, University of British Columbia,

Canada

Reviewed by:

Lisa S. Westerberg, Karolinska Institutet, Sweden Pavel Tolar,

Francis Crick Institute,

United Kingdom

${ }^{*}$ Correspondence: Leopoldo Santos-Argumedo

lesantos@cinvestav.mx

Specialty section:

This article was submitted to B Cell Biology,

a section of the journal

Frontiers in Immunology

Received: 09 August 2017 Accepted: 23 November 2017 Published: 11 December 2017

Citation: López-Ortega O and SantosArgumedo L (2017) Myosin $1 \mathrm{~g}$ Contributes to CD44 Adhesion

Protein and Lipid Rafts Recycling and

Controls CD44 Capping and Cell Migration in B Lymphocytes.

Front. Immunol. 8:1731. doi: 10.3389/fimmu.2017.01731
Cell migration and adhesion are critical for immune system function and involve many proteins, which must be continuously transported and recycled in the cell. Recycling of adhesion molecules requires the participation of several proteins, including actin, tubulin, and GTPases, and of membrane components such as sphingolipids and cholesterol. However, roles of actin motor proteins in adhesion molecule recycling are poorly understood. In this study, we identified myosin $1 \mathrm{~g}$ as one of the important motor proteins that drives recycling of the adhesion protein CD44 in B lymphocytes. We demonstrate that the lack of Myo1g decreases the cell-surface levels of CD44 and of the lipid raft surrogate GM1. In cells depleted of Myo1g, the recycling of CD44 was delayed, the delay seems to be caused at the level of formation of recycling complex and entry into recycling endosomes. Moreover, a defective lipid raft recycling in Myo1g-deficient cells had an impact both on the capping of CD44 and on cell migration. Both processes required the transportation of lipid rafts to the cell surface to deliver signaling components. Furthermore, the extramembrane was essential for cell expansion and remodeling of the plasma membrane topology. Therefore, Myo1g is important during the recycling of lipid rafts to the membrane and to the accompanied proteins that regulate plasma membrane plasticity. Thus, Myosin $1 \mathrm{~g}$ contributes to cell adhesion and cell migration through CD44 recycling in B lymphocytes.

Keywords: B lymphocyte, recycling, cytoskeleton, adhesion molecules, myosin

\section{INTRODUCTION}

The ability of cells to generate polarized distributions of several molecules enables numerous biological process including asymmetric cell division, cell motility, and formation of the immunological synapse. This polarization comprises signaling molecules, GTPases, adhesion molecules, the MHC complex, cytoskeleton-binding proteins, and myosins, among others (1).

Cell migration and cell adhesion are critical processes in cells of the immune system. For example, during inflammation, leukocytes are recruited by activated endothelial cells followed by transmigration, and their establishment in the injured tissue (1). These phenomena require cell adhesion and cell migration. Over these serial processes, the cell undergoes multiple attachments and detachments to endothelial cells (1). These processes are regulated by several proteins, which include adhesion molecules such as integrins and CD44. During migration, the adhesion proteins 
function as traction points that drive the formation and stabilization of membrane projections, thus allowing the movement of cells (2).

During migration, these molecules constantly shuttle between different cell compartments and the plasma membrane; this process is called recycling. This recycling process requires the maintenance of a constant state of equilibrium within the internal cellular membranes and the plasma membrane (3). The vesicular traffic is a complex mechanism involving membrane compartments, which differ in their lipid and protein composition, thereby providing specificity in their content and functions (4). Various proteins, involved in vesicular transport have been described, including clathrin, caveolin, dynamin, GTPases, synaptotagmin, actin, myosins, tubulin, and dyneins (5).

Several traffic pathways have been described, such as, clathrin or caveolin-dependent mechanisms. For example, adhesion molecules migrate to small dynamic subdomains that can be stabilized to form larger specialized caveolin-dependent microdomains (3). These sphingolipid- and cholesterol-enriched lipid microdomains (lipid rafts) recruit several protein components and compartmentalize cellular processes associated with cell signaling and membrane trafficking (4). Furthermore, it has recently been shown that when a cell detaches from a surface, these lipid rafts are rapidly internalized $(5,6)$. After endocytosis, these membranes and associated rafts are delivered into a caveolin-, actin-, and microtubule-dependent pathway to a perinuclear recycling endosome or Golgi apparatus, which serves as a membrane storage compartment (7). In recent years, it has been demonstrated that the caveolin-dependent pathway participates in the endocytosis of integrins $(8,9)$ such as LFA-1 $(10,11)$, and molecules associated with lipid rafts, such as MHC-II (12), CD55, CD59 (13), and CD44 (14).

CD44 is a class I transmembrane glycoprotein, and one of its ligands is hyaluronic acid (HA), a component of the extracellular matrix (15). CD44 interacts with the actin-cytoskeleton via molecules from the Ezrin, Radixin, and Moesin family $(16,17)$. CD44 is involved in many cellular processes such as differentiation and motility of normal cells or cell migration and metastasis in different types of cancer cells $(18,19)$. Previous studies have shown that CD44-deficient mice have abnormalities in myeloidprogenitor migration, bone marrow colonization (20), and homing of lymphocytes to lymph nodes or the thymus (21). CD44 is located at the leading edge and lamellipodia of several cell types in vitro (22).

CD44 and integrins mediate re-adhesion of the cell during cell spreading, cell adhesion, and cell migration. This attachment and detachment is controlled by the endocytosis and exocytosis of proteins resident in lipid rafts (7). This adhesion and re-adhesion cycle that delivers the signaling components and the extra membrane required for cell surface expansion and remodeling of plasma membrane are essential for cell migration $(4,23)$. This process is known to involve small GTPases, but the specific actin-motor proteins (myosins) required to deliver vesicles containing these lipid rafts to the plasma membrane have not yet been identified.

Myosins are a family of proteins characterized by their ability to bind to filamentous actin. These proteins possess ATPase activity, which promotes the hydrolysis of ATP coupled with conformational changes. These changes allow movement along the microfilament. As a result, they are called motor proteins $(24,25)$. Myosins are the primary microfilament-associated motor proteins. They represent likely candidates to mediate the recycling of adhesion molecules. Myosins occur as monomeric or dimeric motors with a diverse range of cellular roles, such as transporters, anchors, or for tension maintenance (26). Class I myosins have eight members (Myola-Myolh) (27-29). Myosin1g (Myolg) is a monomeric class I myosin with a single $\mathrm{N}$-terminal catalytic motor (head) domain, a regulatory neck region that contains IQ-motifs for calmodulin binding, and a C-terminal tail, which directly associates, through a putative pleckstrin homology domain, with phosphatidylinositol 3,4-bisphosphate (30) and phosphatidylinositol 3,4,5-triphosphate (31) in membranes.

Myo1g is expressed in hematopoietic cells and has been shown to localize to the plasma membrane (30). It is important to bind the plasma membrane to the actin-cytoskeleton in lymphocytes (32). It also plays a role in the phagocytosis of opsonizedmicrobeads in macrophages (31) and is involved in cell spreading and cell adhesion in B lymphocytes (33). Furthermore, Myolg is present in several types of vesicles such as endosomes (34) and exosomes in T (35) and B-lymphocytes (36), as determined by mass spectrometry.

Therefore, the objective of this study was to characterize the cellular functions of Myo1g in B lymphocytes. We demonstrate that Myolg is a motor protein that is crucial for the cellular distribution and trafficking of CD44, associated with lipid rafts. Myolg participates in the recycling of vesicles enriched in GPIanchored proteins. Depletion of Myolg leads to a loss of CD44 and lipid rafts from the plasma membrane, which suggests a role for Myolg in the exocytosis of lipid raft membranes and protein associates from an intracellular recycling compartment. These results reveal a novel molecular function, important for cell capping, by which Myolg mediates lipid raft exocytosis to dynamic sites of the plasma membrane.

\section{EXPERIMENTAL PROCEDURES}

\section{Mice and Reagents}

Female C57BL/6J WT or C57BL/6J Myolg-deficient $\left(\right.$ Myolg $\left.^{-/-}\right)$ mice (8-12 weeks of age) (33) were used in all experiments. The mice were produced at the Centro de Investigación y de Estudios Avanzados (Mexico City, Mexico) animal facility. The Animal Care and Use Committee of Centro de Investigación y de Estudios Avanzados approved all experiments. Antibodies and reagents used in this study are as follows: purified rabbit polyclonal immunoglobulin (Ig)G $\alpha$-Myolg (30), rabbit $\alpha$-Myolg (Santa Cruz Biotechnology, Dallas, TX, USA), goat $\alpha$-Myolg (Santa Cruz Biotechnology), rat monoclonal antibodies (mAb) NIM-R1 ( $\alpha$-Thy-1) and NIM-R8 ( $\alpha$-CD44) (37), biotin-labeled $\mathrm{mAb} \alpha$-CD44 (clone IM7) (BD Pharmingen, San Diego, CA, USA), $\alpha$-rat-PE (BD Pharmingen), purified $\alpha$-goat-PE, $\alpha$-rabbit IgG-Alexa488 (Molecular Probes, Eugene, OR, USA), $\alpha$-rabbit IgG-FITC (Jackson ImmunoResearch, West Grove, PA, USA), 
$\alpha$-rabbit IgG-Cy3 (Jackson ImmunoResearch), Streptavidin-Cy3 (Invitrogen, Frederick, MD, USA), TRITC-phalloidin (Molecular Probes), FITC-phalloidin (Sigma Chemical Co, St. Louis, MO, USA), Streptavidin-APC (BD), Pacific Blue $\alpha$-B220 (BD Pharmingen) $\alpha$-IgM (Zymed Laboratories, San Francisco, CA, USA), $\alpha$-Rab5 (Santa Cruz Biotechnology), $\alpha$-CDC42 (Santa Cruz Biotechnology), $\alpha$-CDC42-GTP (New East Biosciences, Brownsville, TX, USA), $\alpha$-RhoA (Santa Cruz Biotechnology), $\alpha$-RhoA-GTP (New East Biosciences), $\alpha$-Actin (Santa Cruz Biotechnology), mAb $\alpha$-CD44 (clone KM201, Abcam Cambridge, UK), $\alpha$-Ezrin (Santa Cruz Biotechnology), $\alpha$-Caveolin (Santa Cruz Biotechnology), purified goat polyclonal $\operatorname{IgG} \alpha$-Rab11 (38), biotinylated cholera toxin subunit B (Life Technologies, Grand Island, NY), Streptavidin-FITC (Sigma), $\alpha$-CD44-PE (BioLegend, San Diego, CA, USA), and $\alpha$-B220-VB421 (BioLegend), Primaquine (Sigma), Lanosterol (Sigma), Cholesterol (Sigma), Golgi-stop (Becton Dickinson, East Rutherford, NJ, USA).

\section{B Lymphocyte Isolation, Activation, and Staining}

Mononuclear cells were isolated from the spleen by FicollHypaque density gradient separation. B cells were enriched by panning, using plastic dishes coated with $\alpha$-Thy- $1 \mathrm{mAb}$ ascites (NIM-R1). For activation, B lymphocytes were activated with Escherichia coli O55:B5 LPS (Sigma) at $40 \mu \mathrm{g} / \mu \mathrm{l}$ and $10 \mathrm{U} / \mathrm{ml}$ interleukin 4 (IL-4) (R\&D Systems, Minneapolis, MN, USA) for $48 \mathrm{~h}$ at $37^{\circ} \mathrm{C}$. For staining, the cells were washed with phosphatebuffered saline (PBS), fixed for $15 \mathrm{~min}$ with $4 \%$ paraformaldehyde (PFA), permeabilized with $0.1 \%$ Triton X-100, and finally incubated with different Abs or fluorescent reagents as previously described by Maravillas-Montero et al. (33).

\section{Induction of Capping}

Primary enriched B cells were treated with NIM-R8, $\alpha$-IgM (Zymed), $\alpha$-transferrin receptor (TfR) (SantaCruzBiotechnology) or HA (Sigma), and incubated for $15 \mathrm{~min}$ at $4^{\circ} \mathrm{C}$. The cells were then washed with cold PBS and $\alpha$-Rat-PE or $\alpha$-Goat-PE, incubating for $60 \mathrm{~min}$ at $37^{\circ} \mathrm{C}$ to induce cross-linking with the antibodies. To stimulate crosslinking with $\mathrm{HA}$, the cells were incubated for $30 \mathrm{~min}$ at $37^{\circ} \mathrm{C}$ with HA-FITC. Finally, the cells were fixed with $4 \%$ PFA and permeabilized with $0.1 \%$ of Triton X-100 to detect Myo1g, caveolin, or GM1 as described below. After staining, the cells were mounted on coverslips treated with poly-L-lysine (Sigma) for microscopy observations. In some experiments, cholesterol was removed in B lymphocytes. Briefly, cells were washed twice with $1 \times \mathrm{PBS}$ and treated with $5 \mathrm{mM}$ of $\mathrm{M} \beta \mathrm{CD}$ (Sigma) for $15 \mathrm{~min}$ at $37^{\circ} \mathrm{C}(15,17)$ or treated with $\mathrm{M} \beta \mathrm{CD}$ plus cholesterol or lanosterol at $1 \mu \mathrm{g} / \mathrm{ml}$ for $30 \mathrm{~min}$ at $37^{\circ} \mathrm{C}$. To block the recycling of adhesion molecules, the cells were washed twice with $1 \times$ PBS and treated with $50 \mu \mathrm{M}$ of chloroquine (16), $0.3 \mathrm{mM}$ of primaquine (39), or $50 \mu \mathrm{M}$ of Golgi-stop (monensin) (40) for $1 \mathrm{~h}$ at $37^{\circ} \mathrm{C}$.

\section{Immunoprecipitation}

Resting, activated, or capping induced-B cells were lysed with RIPA buffer [20 mM Tris-HCl (pH 7.5), $150 \mathrm{mM} \mathrm{NaCl}, 1 \mathrm{mM}$
EDTA, $1 \mathrm{mM}$ EGTA, 1\% Triton X-100, $1 \mu \mathrm{g} / \mathrm{ml}$ leupeptin, $10 \mu \mathrm{g} / \mathrm{ml}$ aprotinin, and $1 \mathrm{mM} \mathrm{PMSF}] 30 \mathrm{~min}$ at $4^{\circ} \mathrm{C}$. After that, the lysates were centrifuged $30 \mathrm{~min}$ at $4^{\circ} \mathrm{C}$ at $18,000 \mathrm{~g}$ and the supernatants were mixed with $\alpha$-Myolg or NIM-R8, using rabbit IgG or rat IgG as isotype controls, respectively. The supernatants were incubated $4 \mathrm{~h}$ at $4^{\circ} \mathrm{C}$ in agitation; then, the complexes were precipitated with protein G-agarose (Life Technologies), maintaining the temperature at $4^{\circ} \mathrm{C}$. Complexes were washed three times with RIPA buffer and boiled in Laemmli buffer. Western blotting was performed under standard conditions.

\section{Lipid Raft Isolation}

For lipid raft isolation, $1 \times 10^{8} \mathrm{~B}$ lymphocytes from WT or $\mathrm{Myolg}^{-/-}$mice (treated or not with M $\beta C D$ ) were washed with icecold PBS and lysed 30 min on ice with $1 \%$ Triton X-100 in TNE buffer containing protease and phosphatase inhibitors (TNE:

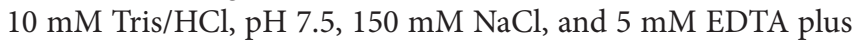
$2.5 \mathrm{mg} / \mathrm{ml}$ each of PMSF, leupeptin, aprotinin, $50 \mathrm{mM}$ sodium fluoride, and $1 \mathrm{mM}$ sodium orthovanadate). The mixture was further homogenized with 10 strokes in a Wheaton loose-fitting dounce homogenizer. Nuclei and cellular debris were pelleted by 10 min centrifugation at $900 \mathrm{~g}$. For the discontinuous sucrose gradient, $1 \mathrm{ml}$ of cleared supernatant was mixed with $1 \mathrm{ml}$ of $85 \%$ sucrose in TNE and transferred to the bottom of a Beckman $14 \mathrm{~mm} \times 95 \mathrm{~mm}$ centrifuge tube. The diluted lysate was overlaid

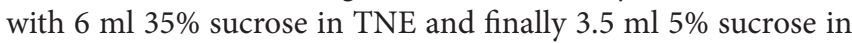
TNE. The samples were centrifuged $20 \mathrm{~h}$ at $200,000 \mathrm{~g}$ and $4^{\circ} \mathrm{C}$. Fractions of $1 \mathrm{ml}$ were collected from the top of the gradient and then analyzed by WB.

\section{FACS Assays}

Resting or activated B-lymphocytes from WT or Myolg ${ }^{-/-}$mice were harvested, then, these cells were washed and adjusted at $1 \times 10^{6}$ cells $/ \mathrm{ml}$ in ice cold 5\% BSA in PBS and incubated $20 \mathrm{~min}$ on ice. After $5 \mathrm{~min}$ centrifugation at $400 \mathrm{~g}$ at $4^{\circ} \mathrm{C}, 1 \mu \mathrm{g} / \mathrm{ml}$ of specific primary antibody or subunit $\mathrm{B}$ of cholera toxin was added and incubated $20 \mathrm{~min}$ at $4^{\circ} \mathrm{C}$ in the dark. The cells were washed with $\mathrm{PBA}\left(\mathrm{PBS}+1 \% \mathrm{BSA}+0.1 \% \mathrm{NaN}_{3}\right)$ twice by centrifugation at $400 \mathrm{~g}$ for $5 \mathrm{~min}$; then, the secondary antibody or reagent was added (depending of each staining) and incubated $20 \mathrm{~min}$ at $4^{\circ} \mathrm{C}$ in the dark. After incubation, the cells were washed three times with PBA (as described above) and finally resuspended in $1 \mathrm{ml}$ of ice cold 1\% PFA. The cells were analyzed by FACS or by confocal microscopy (depending of the experiment design).

\section{CD44 Recycling Assay}

Mononuclear cells were isolated from the spleen by FicollHypaque density gradient separation, these cells were washed three times with cold PBS, and incubated for $30 \mathrm{~min}$ on ice with $1 \mathrm{mM}$ of Lc-Biotin (Pierce, Rockford, IL, USA) in PBS. The reaction was terminated with the addition of $100 \mathrm{mM}$ glycine (Sigma), incubating for $15 \mathrm{~min}$ on ice followed by extensive washing with cold PBS. Biotin-labeled cells were incubated with NIM-R8 followed by $\alpha$-Rat-PE to induce CD44 internalization (as described above). Next, the cells were treated $30 \mathrm{~min}$ at $37^{\circ} \mathrm{C}$ with $0.25 \%$ trypsin (Gibco, Grand Island, NY, USA) to remove surface proteins, followed by the addition of $5 \mu \mathrm{g}$ of unlabeled 
streptavidin (Sigma) and $\alpha$-CD44 (clone IM7) to block the remaining biotinylated CD44 on the surface. Finally, the cells were incubated 10,30 , or $60 \mathrm{~min}$ at $37^{\circ} \mathrm{C}$ to allow the recycling of CD44. After completion of the treatment, the cells were fixed with PFA, stained with streptavidin-FITC (Sigma), $\alpha$-CD44-PE (BioLegend), and $\alpha$-B220-VB421 (BioLegend) and analyzed by flow cytometry.

\section{Proteins Associated to CD44 during Recycling}

As described, B cells were labeled with biotin and then treated with $\alpha$-NIM-R 8 and $\alpha$-Rat IgG to induce the internalization of CD44. The remaining biotinylated CD44 on the surface was removed with trypsin $0.25 \%$ and $5 \mu$ g of unlabeled streptavidin. The cells were extensively washed with PBS and then lysed with RIPA buffer. Biotinylated proteins were precipitated by streptavidin-agarose (Sigma) overnight at $4^{\circ} \mathrm{C}$. After washing three times with RIPA buffer, the streptavidin-agarose beads were mixed with Laemmli buffer and the proteins were resolved in $12 \%$ SDS-PAGE gel and transferred to nitrocellulose membrane for immunoblot analysis using $\alpha$-CD44 (Clone KM201).

\section{Spreading Assays}

Glass slides were coated overnight at $37^{\circ} \mathrm{C}$ with NIMR8 in PBS. The coverslips were blocked with PBS containing $10 \%$ fetal calf serum for $1 \mathrm{~h}$ at $37^{\circ} \mathrm{C}$ and then, washed thoroughly with medium before use. B-lymphocytes from WT or Myolg $\mathrm{g}^{-/-}$mice were transferred without washing to the precoated glass slides and incubated for different time intervals at $37^{\circ} \mathrm{C}$. After incubation, the cells were fixed with $4 \%$ paraformaldehyde for $15 \mathrm{~min}$, washed with PBS, and permeabilized with $0.1 \%$ Triton X-100 in PBS for $10 \mathrm{~min}$. After permeabilization, the cells were washed with PBS, stained with TRITC-phalloidin, and mounted as described previously (41). The slides were observed in a FV300 Olympus microscope, using $60 \times$ objectives and the images were analyzed by NIH ImageJ software (http://rsbweb.nih.gov/ij).

\section{D Migration Assay}

A Zigmond chamber (Neuro Probe, Inc., Gaithersburg, MD, USA) was used to evaluate migration. Briefly, one million B-lymphocytes were suspended in $0.5 \mathrm{ml}$ of RPMI 1640 supplemented with 10\% FBS (Life Technologies, Carlsbad, CA, USA) and immediately plated onto glass coverslips previously coated with $2.5 \mu \mathrm{g} / \mathrm{ml}$ of fibronectin (Takara). The coverslips were incubated $30 \mathrm{~min}$ at $37^{\circ} \mathrm{C}$ in $5 \% \mathrm{CO}_{2}$ to allow cell attachment. The coverslips, with the cells attached, were gently washed with $2.0 \mathrm{ml}$ PBS. One hundred microliters of supplemented RPMI 1640 was pipetted onto the coverslips, which in turn, were placed upside-down onto the Zigmond slides. One of the grooves, in the Zigmond chamber, was filled with supplemented medium $(80 \mu \mathrm{l})$ and the chamber was placed under a microscope. A baseline image was obtained at $20 \times$ magnification and the other groove was then filled with CXCL13 (50 ng), also dissolved in supplemented medium. Digital images of the cells were taken every $20 \mathrm{~s}$ for $30 \mathrm{~min}$, maintaining the temperature of the room at $35-39^{\circ} \mathrm{C}$. Migration tracks were traced for at least 30 lymphocytes of each condition, in three independent experiments, using NIH ImageJ software with chemotaxis and migration tool 2.0 (Ibid). From these data, trajectories and migration speed were calculated.

\section{Hyaluronic-Acid Endocytosis Assay}

B-cells were incubated $60 \mathrm{~min}$ at $4^{\circ} \mathrm{C}$ with HA-FITC, and then incubated at $37^{\circ} \mathrm{C}$ during different intervals of time before fixation. Levels of cell-associated HA-FITC were determined by FACS analysis, using a CyAn ADP flow cytometer (Beckman Coulter); the flow cytometry data were analyzed using FlowJo software.

\section{Nucleofection of B-Lymphocytes}

The nucleofection of primary B lymphocytes was performed under manufacturer conditions (Lonza VPA-1010 kit). Briefly, panning-enriched B-lymphocytes were activated with LPS overnight. After that, the cells were placed at room temperature with $\mathrm{B}$ cell nucleofection solution $\left(3 \times 10^{6} \mathrm{~B}\right.$ cells per $\left.100 \mu \mathrm{l}\right)$. Five micrograms of Full-Length Myo1g-Green Fluorescent Protein (Myolg-FL) plasmid were added. The mixture was immediately transferred into an Amaxa cuvette and Nucleofector Amaxa Z-001 program was used. Nucleofected B-lymphocytes were placed in pre-warmed supplemented RPMI containing LPS + IL4, the cells were incubated $48 \mathrm{~h}$ at $37^{\circ} \mathrm{C}$ in $5 \% \mathrm{CO}_{2}$.

\section{Endothelial Transmigration}

Transwell chamber filters (5 $\mu \mathrm{M}$, Corning) or 24-well plates (control) were coated with an attachment factor (Gibco) for $1 \mathrm{~h}$ at $37^{\circ} \mathrm{C}$. The solution was then removed and the filters were dried. These filters were seeded with $2.5 \times 10^{4}$ endothelial MLEC cells (42) per filter in $200 \mu \mathrm{l}$ of complete DMEM. Two wells out of a 24-well plate were used to monitor the confluency of MLEC cells and the integrity of the endothelial barrier. The cells were incubated for 2 days at $37^{\circ} \mathrm{C}$. When the cells reached confluency, the monolayers were treated with $5 \mathrm{nM}$ TNF- $\alpha$ overnight. After incubation, the filters were washed with DMEM and the top and the bottom chambers were filled with 50 and $600 \mu \mathrm{LMEM}$ (without FBS), respectively. CXCL13 $(1 \mu \mathrm{g} / \mu \mathrm{l})$ was added in some of the bottom chambers. In some cases, CFSE-labeled resting or activated $\mathrm{B}$ cells were pretreated with $\alpha$-CD 44 clone IM7 for $1 \mathrm{~h}$ or left untreated. Then, $4 \times 10^{5} \mathrm{~B}$ cells were added on top of each filter and incubated for $4 \mathrm{~h}$. The filters were then carefully removed and the cells at the top and the bottom of each well were stained with $\alpha-B 220-\mathrm{PB}$ and analyzed by flow cytometry.

\section{In vivo Homing Assay}

LPS plus IL-4 activated B cells from Myo1 g ${ }^{-1-}$ or WT mice were labeled with either $0.1 \mu \mathrm{M}$ (low concentration) or $0.6 \mu \mathrm{M}$ (high concentration) CFSE (Invitrogen); in some experiments, these cells were preincubated with $\alpha-\mathrm{CD} 44$ clone IM7. The cells were mixed at a 1:1 ratio and injected, via tail vein (at $1 \times 10^{7}$ cells per mouse) into recipient mice $(\mathrm{C} 57 \mathrm{BL} / 6)$. Mice were sacrificed $2 \mathrm{~h}$ after the adoptive transfer, and spleens and inguinal lymph nodes were excised. B cells were surface stained with $\alpha$-B220-PB (BioLegend). The cells were analyzed on a CyAn ADP flow cytometer (Beckman Coulter) for the presence of 
labeled cells and for expression of the B220 marker. The recovery ratios of each population were calculated as percentages using FlowJo software. To validate the procedure, in each experiment, $\mathrm{Myolg}^{-/-}$only or WT only cells were labeled with both high and low concentrations of CFSE and injected into recipient mice. Ratios close to 1:1 of the high and low CFSE labeled cells in the lymph nodes of the recipient mice indicate that the homing behavior of the cells was not significantly changed by the dye.

\section{Uptake Assays}

Panning-enriched B cells $\left(1 \times 10^{6}\right.$ cells per well in $500 \mu \mathrm{l}$ of supplemented RPMI 1640 medium) were incubated for $30 \mathrm{~min}$ at $37^{\circ} \mathrm{C}$ in $5 \% \mathrm{CO}_{2}$ in 24 -well plates with $\mathrm{HA}$ coated $0.5 \mu \mathrm{m}$ polystyrene fluorescent microspheres (43) (Molecular Probes), at bead-to-cell ratio of 10:1. The cells were then harvested and washed with PBS before the addition of $0.5 \mathrm{ml}$ of a Trypan Blue solution $(50 \mu \mathrm{g} / \mathrm{ml})$ to quench the fluorescence of uningested particles. After a brief incubation for $2 \mathrm{~min}$, the dye was extensively washed with PBS and cells were stained with $\alpha-B 220-\mathrm{PB}$. The cells were then fixed and analyzed on a CyAn ADP flow cytometer (Beckman Coulter). In some experiments, the cells were treated with $\alpha-$ CD44 monoclonal antibody, clone IM7.

\section{Adhesion Assays}

Hyaluronic acid (Sigma) or $\alpha$-IgM (Zymed) coated 96 well polystyrene plates (Nalge Nunc International) were incubated for $1 \mathrm{~h}$ at $37^{\circ} \mathrm{C}$. The plates were then washed twice with PBS before adding $4 \times 10^{5}$ panning-enriched B cells in $200 \mu \mathrm{l}$ of RPMI 1640 per well. The cells were adhered for $1 \mathrm{~h}$ at $37^{\circ} \mathrm{C}$. The plates were then washed with $300 \mu \mathrm{l}$ of PBS, fixed with $4 \%$ paraformaldehyde for $10 \mathrm{~min}$, before adding crystal-violet $(7.5 \mathrm{~g} / \mathrm{l}$ crystal-violet, $2.5 \mathrm{~g} / \mathrm{l}$ $\mathrm{NaCl}, 1.57 \%$ formaldehyde, $50 \%$ methanol) for an additional $5 \mathrm{~min}$. The cells were washed extensively eight times with distilled water, solubilized with $10 \%$ SDS, and the amount of dye remaining in the plates was recorded at $540 \mathrm{~nm}$ (Multiskan Ascent, Thermo Scientific, Waltham, MA, USA). After subtraction of the non-specific dye bound to empty wells, absolute binding was calculated. The absorbance was determined in at least four wells per condition, in three independent experiments.

\section{Statistical Analysis}

Results are presented as mean $\pm \mathrm{SD}$. An unpaired two-tailed Student's $t$-test or one-way ANOVA were used to assess statistical significance between groups. The $P$ values obtained and the number of samples or cells (n) used are mentioned in each figure legend.

\section{RESULTS}

\section{Myo1g Deficiency Affects the Polarization of CD44 in B Cells}

To determine whether the absence of Myolg affects the polarization of CD44 (capping), B cells from wild type (WT) and

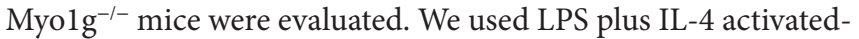
B lymphocytes in most experiments, because in non-activated B lymphocytes, it is difficult to record morphological changes induced by CD44 crosslinking or HA treatment (33, 37, 41, $44,45)$. The activation triggers several signaling pathways; among others, STAT6 activation has shown to increase the number and length of membrane-protrusions, as well as the motility, of $\mathrm{B}$ lymphocytes (46).

The cells were stimulated $48 \mathrm{~h}$ with LPS + IL- 4 and then incubated with the NIM-R8 antibody to induce CD44 polarization. Confocal microscopy demonstrated that CD44 had reduced mobility to the site of crosslinking in cells lacking Myolg (Figure 1A, white arrows). To quantify these defects, the percentage of cells showing polarized structures was determined, demonstrating a reduction in the percentage of cells with full caps in Myolg-deficient B cells (Figure 1B). In fact, the distribution of CD44 in Myolg-deficient B cells was scattered in patches (Figure 1C, white arrows). The same experiments were performed for several molecules such as TfR (47) and IgM (48-53). The results demonstrated that these molecules did not show defects in their polarization (Figure 1D). CD44 is the main receptor of HA and this extracellular matrix component induced a strong capping in lymphocytes (54); hence, HA-capping assays were performed for both groups of B lymphocytes. A similar pattern of scattered patches as in Myolg-deficient B lymphocytes was also observed (Figure 1E). To quantify these defects, the percentage of cells showing capping was determined, demonstrating a reduced percentage of cells with full caps (Figure 1F).

It was noted that the size of the cap in Myolg-deficient B cells was larger than that in WT B lymphocytes (Figure S1A in Supplementary Material). Therefore, the size of the cap was calculated through an index in which the extent of the cap was divided between the circumference of the cell. This parameter indicated the agglomeration of molecules at that site. The results showed that during capping, Myo1g-deficient B cells have a less uniform distribution of CD44 than WT B cells (Figure S1B in Supplementary Material).

Several studies have demonstrated the importance of the actin-cytoskeleton in the polarity of molecules (55-57). Therefore, we evaluated the polarization of actin to the CD44 capping site. The results demonstrated the accumulation of actin to the CD44 capping site (Figure S2A in Supplementary Material). Cytochalasin E (a drug that blocks polymerization and depolymerization at the barbed ends of actin filaments) was also used to examine the role of actin polarization in CD44 capping. Cytochalasin E treatment negatively affected CD44polarization (Figure S2B in Supplementary Material). This effect was quantified showing an almost complete inhibition of CD44 capping by Cytochalasin E (Figure S2C in Supplementary Material).

Previous studies have demonstrated the accumulation of myosins at the gathering sites of several molecules (41). To investigate whether Myo1g actively participates in the mobilization of CD44, cross-linking with the NIM-R8 antibody was performed, to find Myolg at the site of polarization. Most cells showed Myolg at the CD44 cap. In contrast, Myolg did not congregate with IgM (Figure 2A). To evaluate polarization, an index of the mean fluorescence intensity (MFI) in the cap divided by the MFI outside the cap was calculated-this 







\section{FIGURE 1 | Continued}

The absence of Myo1g affects the polarization of CD44 in B cells. (A) Confocal images of LPS plus IL4-activated WT or Myo1g ${ }^{-/-}$B cells. Arrows illustrate CD44 localization in B lymphocytes (scale bar $60 \mu \mathrm{m}$ ). (B) Percentage of cells with CD44-capping (50 cells were counted per experiment in four independent experiments, 200 cells per data set). (C) Enlarged confocal images of LPS plus IL4-activated WT or Myo1g ${ }^{-/-}$B cells. Arrows illustrate CD44 localization in B lymphocytes (scale bar $5 \mu \mathrm{m}$ ). Graphs of transferrin receptor (TfR), or IgM-capping (50 cells were counted per experiment in three independent experiments, 150 cells per data set). (D) Images of randomly selected files were taken and the percentage of B lymphocytes with capping was calculated (50 cells were counted per experiment in 4 independent experiments, 200 cells per data set). One-way ANOVA tests were used in (B,D) graphs, values are mean \pm SD (*** $P<0.001)$. (E) Confocal images of LPS plus IL4-activated from WT or Myo1g ${ }^{-/-}$B cells. Arrows illustrate hyaluronic acid (HA) localization in B lymphocytes (scale bar 60 $\mu$ m). (F) Percentage of cells with HA-capping; images of randomly selected files were taken, and the percentage of B lymphocytes with capping was calculated. A total of 200 cells was analyzed. Student's $t$-test test was used in this graph, values are mean \pm SD (50 cells were counted per experiment, in four independent experiments, 200 cells per data set) $\left({ }^{\star} P<0.05\right)$.

A
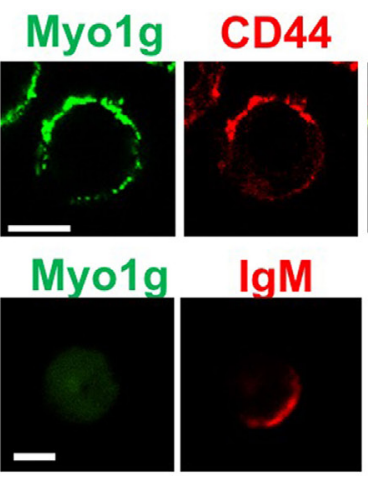

IgM

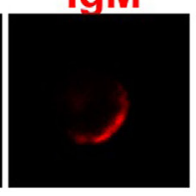

C

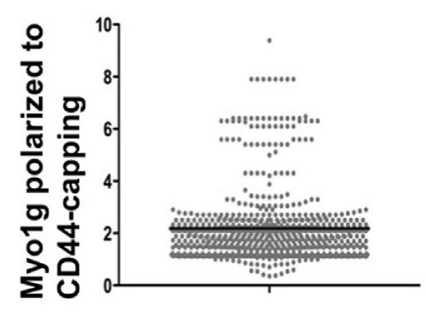

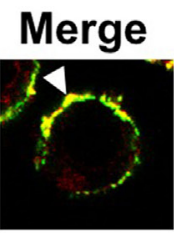

Merge

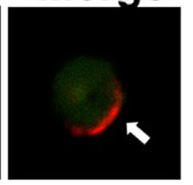

B

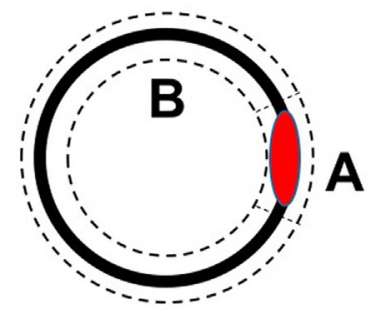

D

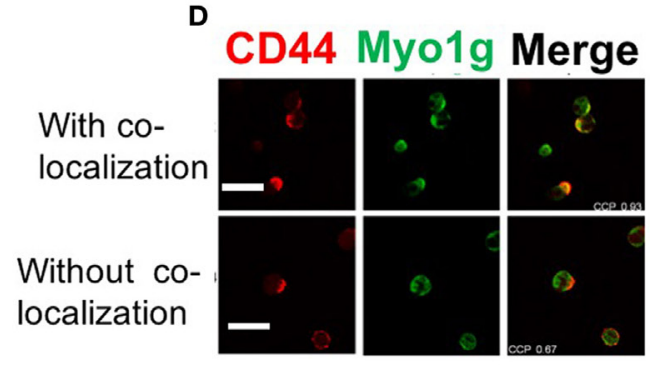

E

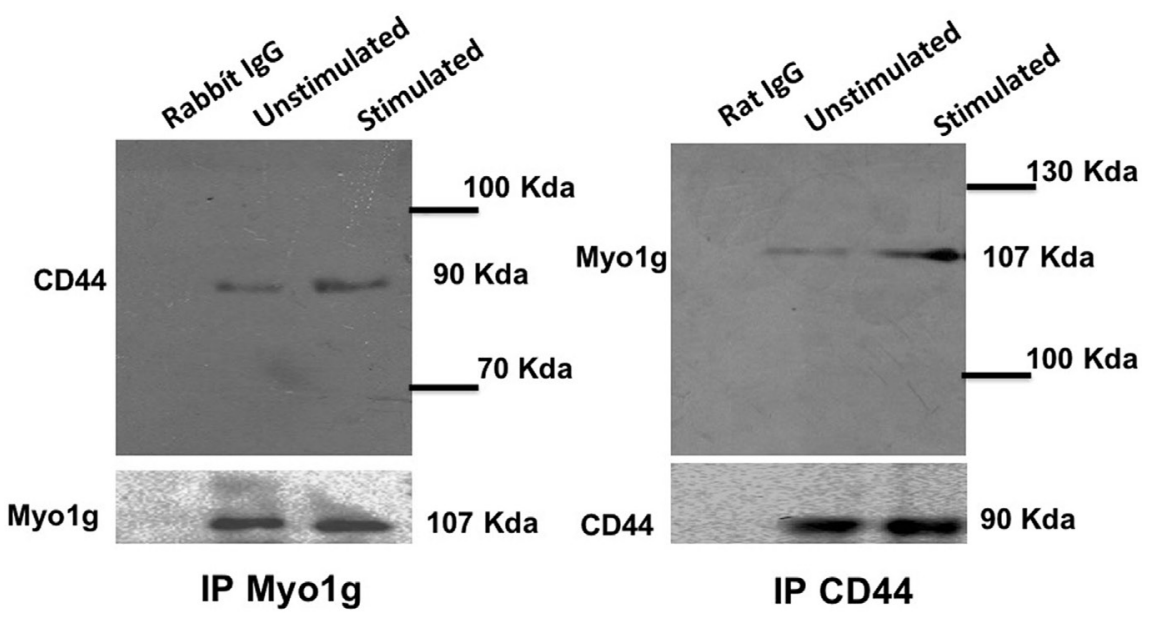

FIGURE 2 | Myo1g is polarized to the capping site of CD44. (A) Confocal images of LPS plus IL4-activated WT or Myo1g ${ }^{-/-}$B cells. Arrows indicate polarization of Myo1g at the CD44-capping site (scale bar $5 \mu \mathrm{m}$ ). (B) Schematic illustration to calculate the polarization index, where A corresponds to the mean fluorescence intensity (MFI) in the polarized region, and B is the MFI in the rest of the cell. The MFI from A is divided by B. If the value is greater than 1.5, the co-localization is considered positive; values less than 1.5 are considered negative. (C) Polarization coefficient of Myo1g and CD44 derived from the analysis of B lymphocytes ( 80 cells were counted per experiment, in 3 independent experiments, 250 cells per data set), values are mean \pm SD. (D) Confocal images of B cells with CD44-capping (scale bar $60 \mu \mathrm{m}$ ). (E) Immunoprecipitation with $\alpha$-Myo1g or $\alpha$-CD44. 
coefficient represents the amount of Myo1g polarized to CD44capping site (Figure 2B). Indexes above 1.5 represented positive co-capping. With the crosslinking of CD44, many cells showed positive co-capping (Figure 2C). In some cells, Myolg did not co-localize on the cap but rather on the opposite side of the cell (Figure 2D). The coefficient of co-localization between CD44 and Myo1g showed that $63 \%$ of lymphocytes presented co-clustering of both molecules (data no shown). This indicates a selective role of Myolg in the mobilization of CD44, which contrasts with IgM polarization. This mobilization appears to be independent of lipid raft clustering (56).

Then, to evaluate if Myolg was present in the mobilization complexes of CD44, immunoprecipitation assays for Myolg and CD44, in resting and activated lymphocytes, were performed. The results demonstrated that Myolg co-immunoprecipitated with CD44 and vice versa (Figure 2E). To further analyze this association, activated B lymphocytes were stimulated with HA (its natural ligand) and then, CD44 was immunoprecipitated to search if Myolg was increased when CD44 was bound with its ligand. As shown Figure S3A in Supplementary Material, Myo1g is associated with CD44 irrespective of ligand occupancy.

Studies indicate that recycling is required for the polarization of some surface molecules (58-61). We analyzed the internalization of CD44 using HA as ligand, we observed the reduction of CD44 on the plasma membrane at $10 \mathrm{~min}$; however, the cells partially recovered CD44 levels from $20 \mathrm{~min}$. These data suggest a recycling of CD44 in response to HA binding (Figure S3B in Supplementary Material). Next, B lymphocytes treated with primaquine, monensin (Golgi-stop), or chloroquine [drugs that blocks cellular recycling $(39,62-67)]$ were analyzed for CD44capping. The results showed impaired formation of CD44-caps in drugs-treated cells (Figure S4A in Supplementary Material). To quantify the effect of reagents, the percentage of cells showing capping was determined, demonstrating a significant reduction (Figure S4B in Supplementary Material).

Previous reports have shown that mobilization of CD44 during cell migration is caveolin- and lipid rafts-dependent. Therefore, we analyzed caveolin and CD44 co-capping in B cells. The results showed the presence of caveolin at the gathering site of CD44 (Figure 3A). Based on the polarization index described above, an increase in caveolin MFI was observed in the CD44cap (Figure 3B). Furthermore, Myo1g co-localized with caveolin (Figure 3C). We also calculated the Myolg-caveolin polarization index, which was above 1.5 in most cells (Figure 3D). To further corroborate these results, an immunoprecipitation assay of Myo1g, using $\alpha$-CD44-crosslinked B cells was performed. The presence of caveolin in the immunoprecipitated fraction was observed, indicating the presence of CD44, caveolin, and Myolg in the same fractions (Figure 3E).

During capping, lipid rafts are important in the mobilization of several molecules (68-71). Some studies have demonstrated a strong interaction between caveolin and lipid rafts (72-76). As a surrogate for lipid rafts, GM1 was identified using subunit B of cholera toxin (CTB) during CD44-capping. GM1 was associated with CD44 and Myo1g (Figure 3F). The Myo1g-GM1 polarization index was calculated, showing a polarization index above 1.5 in most cells (Figure 3G). To complement and extend these results,
CD44-capping was induced with HA, the natural ligand of CD44, and Myo1g, caveolin, and lipid rafts (GM1) were searched at the HA-capping site (white arrows, Figure S5B in Supplementary Material). Colocalization index was quantified in Figure S5B in Supplementary Material.

To further evaluate the role of lipid rafts in the mobilization of CD44, B cells were treated with methyl- $\beta$-cyclodextrin $(M \beta C D$, cholesterol-sequestering drug). Cholesterol-depleted cells were stimulated with the NIM-R8 antibody plus $\alpha$-Rat IgG-PE and visualized by confocal microscopy. Cholesterol-depleted cells showed less polarization of CD44. Notably, most cells did not present CD44-capping (Figures 3H,I). Additionally, we treated cholesterol-depleted B lymphocytes with lanosterol [a sterol that replaces cholesterol in plasma membrane but does not support the lipid rafts formation (77)]. Replacement with lanosterol showed an impaired formation of capped-structure (Figures 3H,I). Interestingly, the pattern of CD44 localization was in patches (white arrows), a strikingly similar phenotype to that observed in Myolg-deficient B cells (Figure 1C). To corroborate the crucial role of lipid rafts in CD44-polarization in B-lymphocytes, we added cholesterol to $\mathrm{M} \beta \mathrm{CD}$-treated cells, using $5 \mathrm{mM} \mathrm{M} \beta \mathrm{CD}$ and 1,2 , and $5 \mu \mathrm{g} / \mu \mathrm{l}$ concentrations of cholesterol. As depicted in Figure S6 in Supplementary Material, CD44-polarization was recovered when cholesterol was added. Of note, cholesterol at higher concentrations seems to partially interfere with CD44-polarization. It is known that the increase in cholesterol drives alterations in plasma membrane rigidity (78), this modification may induce changes in shape, adhesion, locomotion (79), and probably vesicular traffic of adhesion molecules (such as CD44) in the cells. We analyzed spreading of $\mathrm{B}$ cells (another process in which lipid rafts are crucial), using $\mathrm{M} \beta \mathrm{CD}$-treated $\mathrm{B}$ lymphocytes reconstituted or not with cholesterol or lanosterol. We registered reduction of spreading in $\mathrm{M} \beta \mathrm{CD}$-treated $\mathrm{B}$ cells; in contrast, $\mathrm{M} \beta \mathrm{CD}$-treated $\mathrm{B}$ cells, reconstituted with cholesterol but not with lanosterol recovered the ability to spread and to form dendrite. Cholesterol, on its own, reduced spreading of B-cells (Figures S7A,B in Supplementary Material).

\section{The Absence of Myo1g Redistributes CD44 from the Cell Surface to Intracellular Membranes}

In a previous study, we showed that Myolg is present in specialized lipid domains at the plasma membrane (33). During cell migration, CD44 is associated with microdomains. Therefore, we investigated the role of Myolg in regulating CD44 trafficking and distribution. First, the localization of CD44 on the surface of Myolg-deficient cells was evaluated. Resting B cells of both WT and Myolg $\mathrm{g}^{-/-}$mice have similar amounts of CD44 on the surface. In sharp contrast, LPS plus IL4-activated B cells from Myo $1 \mathrm{~g}^{-/-}$demonstrated a substantial decrease in CD44 on the plasma membrane, and this protein accumulated inside the cells (Figures 4A,B). Similar results were observed using HA-FITC to measure the levels of CD44 on the surface. B cells were pretreated with $\alpha$-CD 44 clone IM7, which blocks the interaction between CD44 and HA. Consequently, impaired binding 


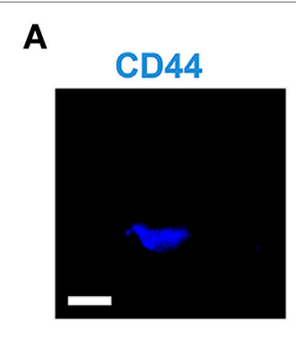

C
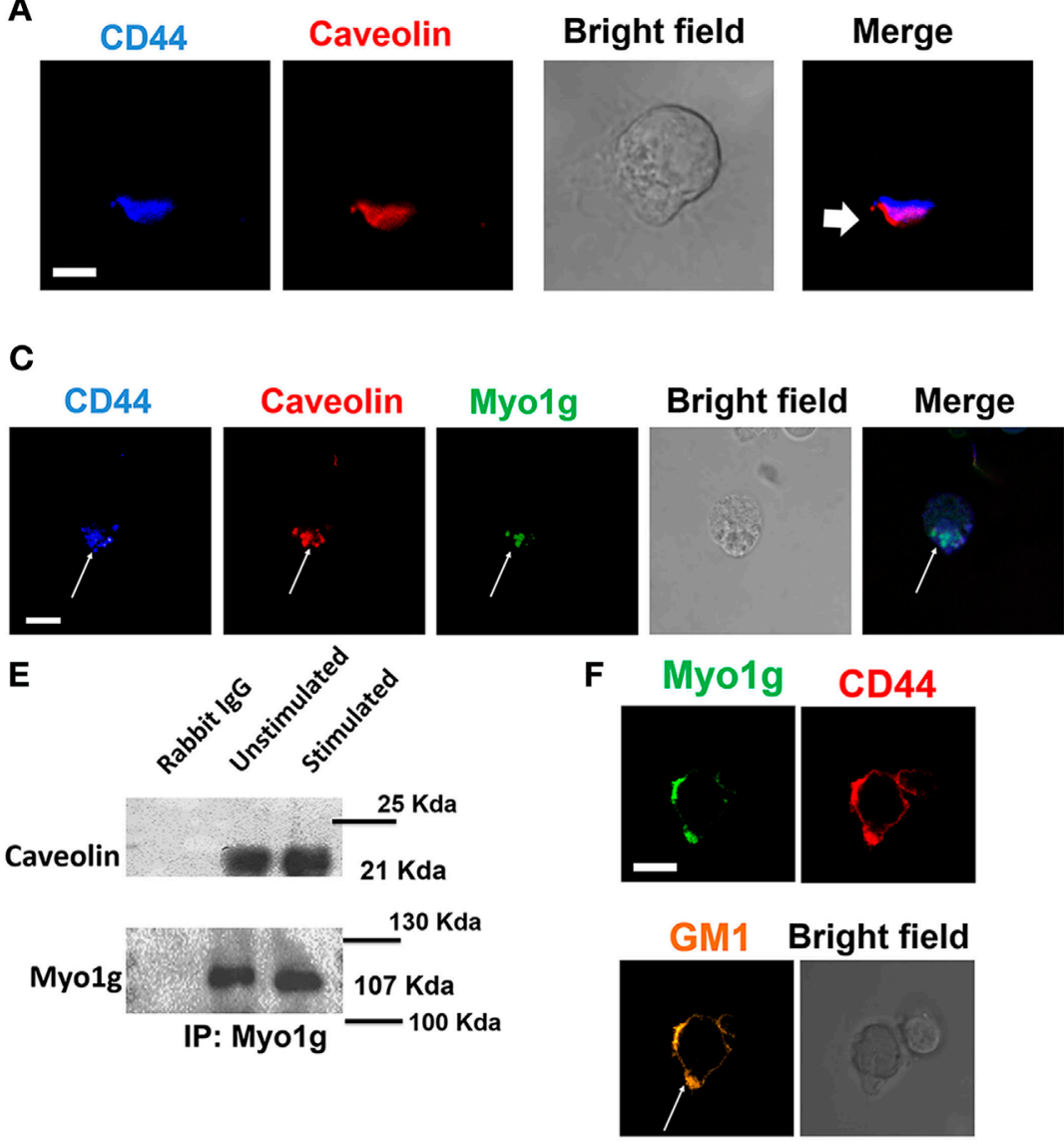

B

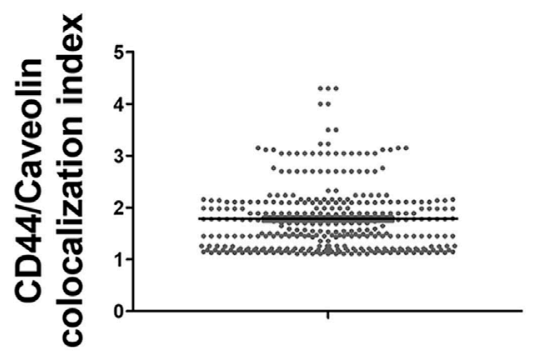

D
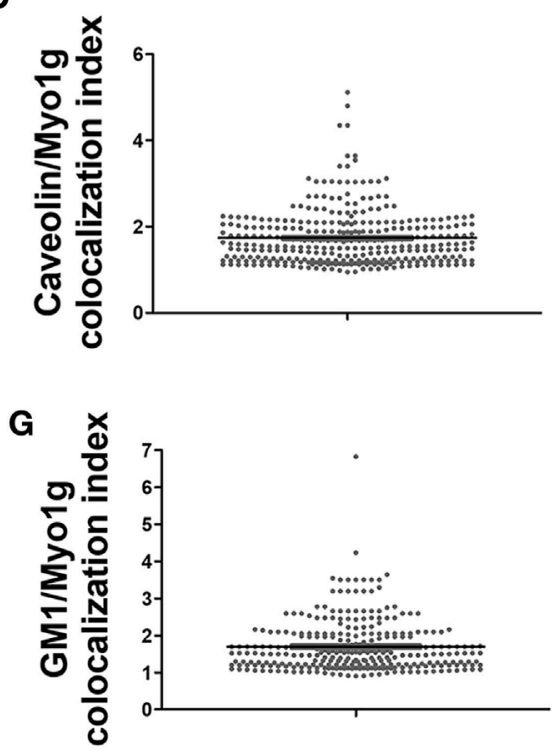
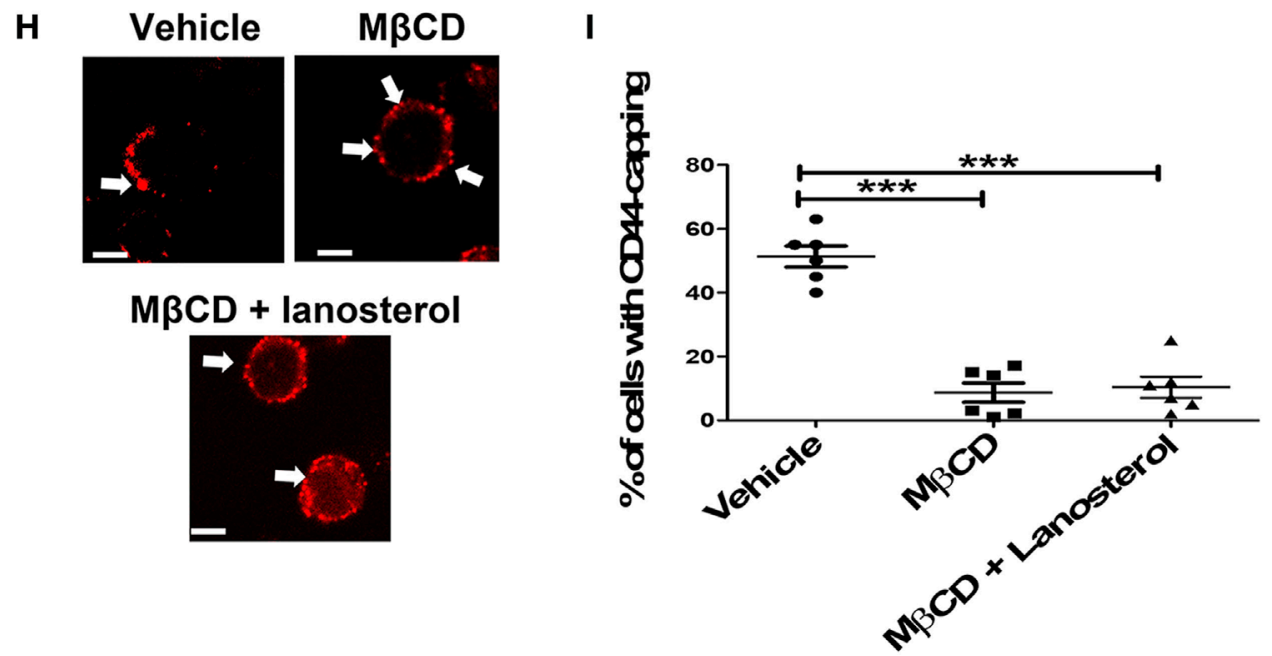

FIGURE 3 | Myo1g is present in the mobilization complex of CD44. (A) Confocal images of LPS plus IL4-activated WT B cells. Arrows illustrate the polarization of caveolin to the CD44-interaction site (scale bar $5 \mu \mathrm{m}$ ). (B) Polarization coefficient of caveolin and CD44, derived from the analysis of a total of 300 cells with capping from three independent experiments (100 cells were counted per experiment), values are mean \pm SD. (C) Confocal images of LPS plus IL4-activated WT B cells. Arrows illustrate the polarization of Myo1g and caveolin to the CD44-interaction site (scale bar $5 \mu \mathrm{m})$. (D) Polarization coefficient of caveolin and Myo1g ( 80 cells were counted per experiment, in 3 independent experiments, 250 cells per data set), values are mean \pm SD. (E) Immunoprecipitation with $\alpha$-Myo1g or $\alpha$-Rabbit (as isotype control) of LPS plus IL4-activated B cells. (F) Confocal images of LPS plus IL4-activated WT B cells. Arrows illustrate the polarization of GM1 (lipid rafts) to the CD44-interaction site (scale bar $5 \mu \mathrm{m}$ ). (G) Polarization coefficient of GM1 and Myo1g derived from the analysis of B lymphocytes ( 70 cells were counted per experiment, in 3 independent experiments, 200 cells per data set), values are mean \pm SD $(n=3)$. (H) Confocal images of LPS plus IL4-activated WT or Myo1g ${ }^{-/}$ B cells. Arrows indicate the localization of CD44 in B cells pretreated with M $\beta C D(5 \mathrm{mM})$ with or without lanosterol (1 $\mu \mathrm{g} / \mu \mathrm{l})$ (scale bar $5 \mu \mathrm{m})$. (I) Percentage of cells with CD44-capping. Images of randomly selected files were taken and the percentage of B cells with capping was evaluated $(n=6)$, one-way ANOVA test was used in this graph values are mean $\pm \mathrm{SD}\left({ }^{\star \star \star} P<0.001\right)$. 


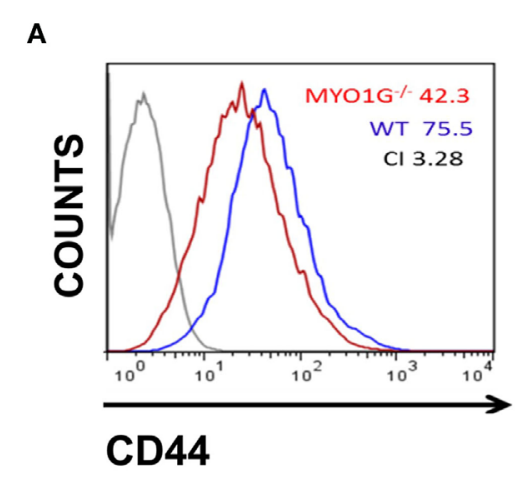

D

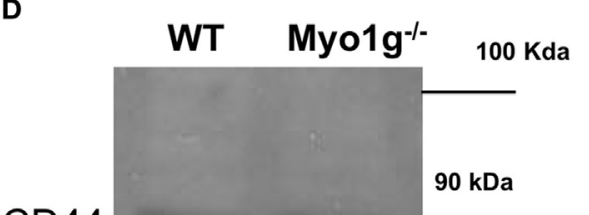

CD44

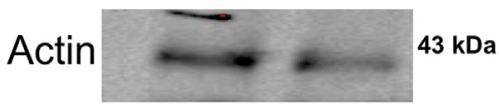

G

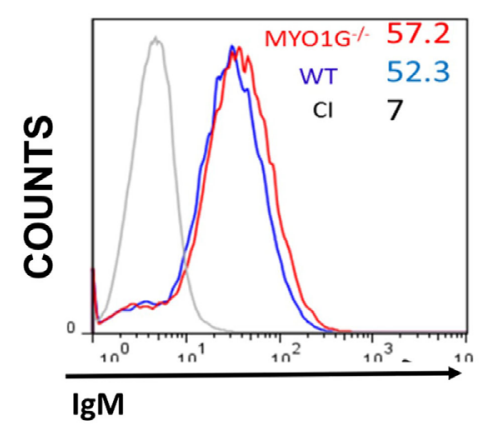

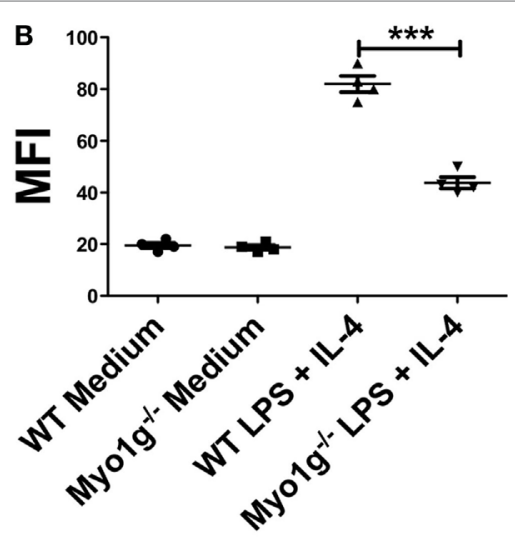

E

CD44 Actin Merge

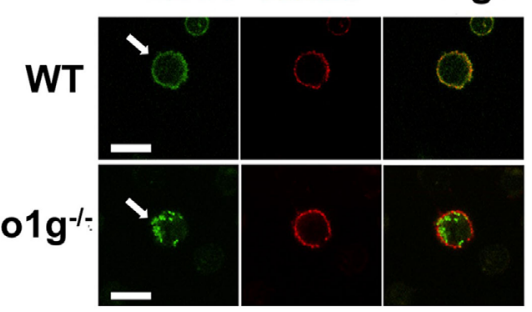

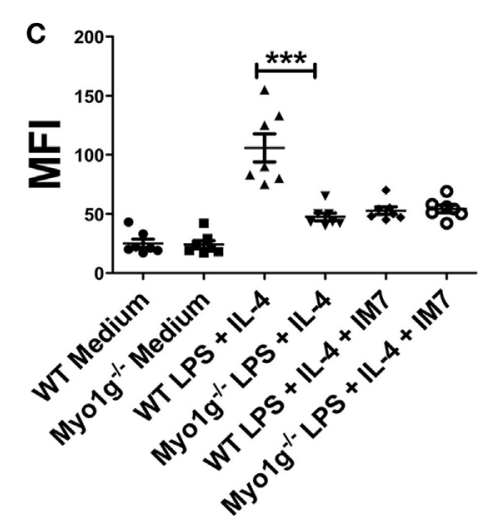

$\mathbf{F}$

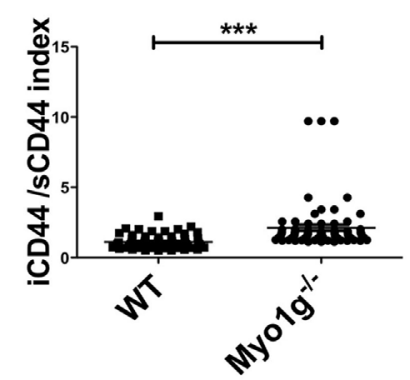

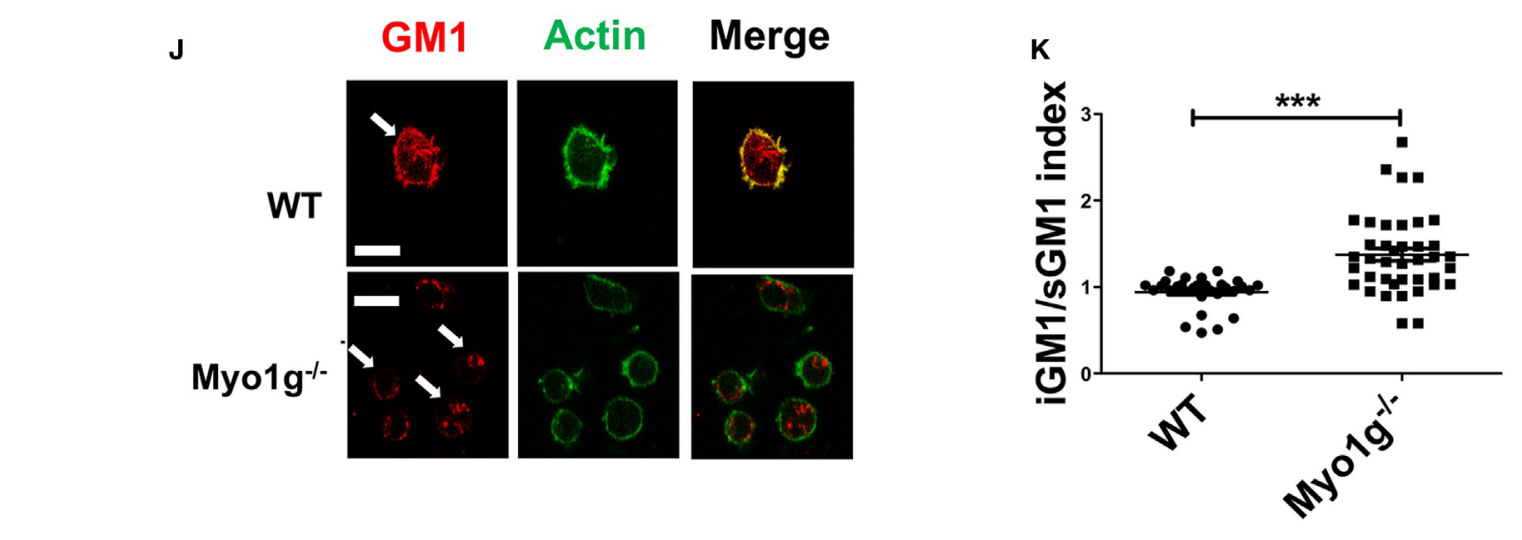

FIGURE 4 | Continued
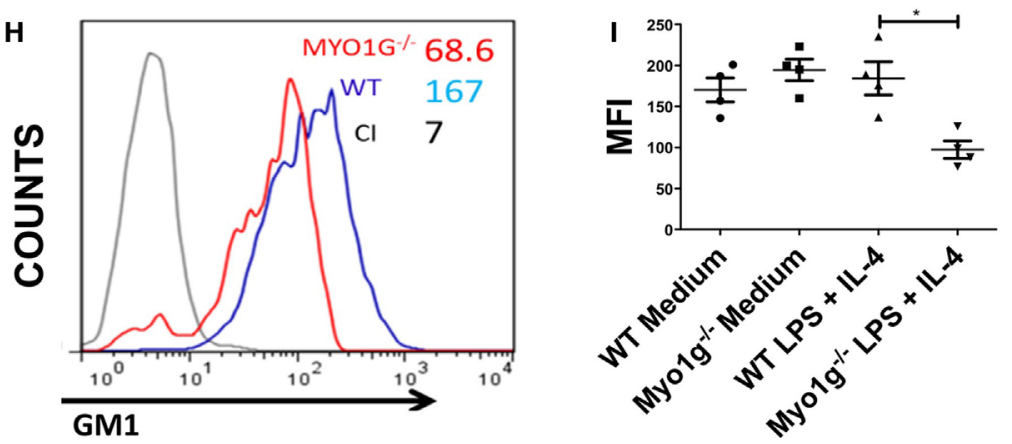
FIGURE 4 | Continued

The absence of Myo1g decreases the amount of CD44 and lipid rafts on the surface of B cells. (A) Expression of CD44 in LPS plus IL4-activated B cells from WT or Myo1g-deficient mice. The graph shows the expression of CD44 in B lymphocytes (10,000 events in a gate of B220 + B cells). (B) Expression of CD44 in resting or activated B cells, one-way ANOVA test was used in these experiments, values are mean \pm SD $\left(^{\star \star \star} P<0.001\right)(n=4)$. (C) Binding of hyaluronic acid $(\mathrm{HA}-\mathrm{FITC})$ to resting or LPS plus IL4-activated B lymphocytes from WT or Myo1g-deficient B lymphocytes. HA binding was blocked using the IM7 mAb. One-way ANOVA test was used in these experiments, values are mean $\pm \mathrm{SD}\left({ }^{\star \star \star} P<0.001\right)(n=7)$. (D) Immunodetection of CD44 in LPS plus IL4-activated B lymphocytes; $\alpha$-CD44 (clone KM201) was used for western blotting. (E) Confocal images of LPS plus IL4-activated WT or Myo1 g ${ }^{-/-}$B cells. (F) The localization of CD44 as cytosol/plasma membrane index was calculated [mean fluorescence intensity (MFI) in the plasma membrane was divided by MFI in the cytosol] ( 30 cells were counted per experiment, in three independent experiments, 100 cells per data set). Student's $t$-test was used in these experiments, values are mean \pm SD ( $\left.{ }^{\star \star} P<0.001\right)$. (G) IgM or (H) GM1 in LPS plus IL4-activated B lymphocytes from WT or Myo1g-deficient B cells, the graphs show the expression of GM1 in B lymphocytes (10,000 events in a gate of B220 + B cells). (I) GM1 staining, one-way ANOVA test was used in these experiments, values are mean \pm SD ( $\left.{ }^{\star} P<0.05\right)(\sim 60$ cells were counted per experiment, in four independent experiments, 250 cells per data set). (J) Confocal images of permeabilized LPS plus IL4-activated WT or Myo1g ${ }^{-/}$ B cells. Arrows indicate the localization of GM1 in B lymphocytes (scale bar $5 \mu \mathrm{m})$. (K) Intracellular versus plasma membrane GM1 ( 30 cells were counted per experiment, in 3 independent experiments, 100 cells per data set), Student's $t$-test was used in these experiments, values are mean \pm SD ( ${ }^{* *} P<0.001$ ).

of HA-FITC to B cells from Myo1g-/- mice was observed (Figure 4C). Remarkably, the expression of CD44 in whole cells was similar (Figure 4D) indicating that the missing CD44 on the surface was retained inside the cell. This hypothesis was corroborated by confocal microscopy observations in permeabilized B lymphocytes (Figure 4E). To quantify the presence of CD44 inside or outside the cell, an intracellular/membrane index was calculated (Figure 4F). This index was quantified by MFI of CD44 inside, this value was divided between MFI of CD44 in surface. The data indicated an increased presence of CD44 inside Myo1g-deficient B cells. To rule out a generalized deficiency of membrane proteins, the presence of $\operatorname{IgM}$ on the cell-surface of both groups of B lymphocytes was analyzed, and both demonstrated similar expression of membrane proteins (Figure 4G).

Because the absence of functional Myolg leads to a reduction in CD44 on the cell surface, and since this molecule is recycled in a lipid raft-dependent mechanism, the level of lipid rafts at the plasma membrane of Myolg-deficient mice was analyzed. Activated and resting B lymphocytes were labeled with biotinCTB and streptavidin (Figures $\mathbf{4 H}, \mathbf{I}$ ). Permeabilized B cells from $\mathrm{Myolg}^{-/-}$mice showed reduced staining with CTB compared to B cells from WT mice. Staining with CTB was observed inside Myo1g-deficient B lymphocytes (Figure 4J). The intracellular/ plasma membrane index demonstrated an increased presence of intracellular GM1 in Myo1g-deficient B cells (Figure 4K). These data indicate that Myolg deficiency affects the localization of lipid rafts. Taken together, these findings suggest a role for Myolg in either recycling or exocytosis of lipid raft-enriched membranes from the intracellular membrane compartments back to the cell surface.

\section{Myo1g Participates in the Recycling Complex of CD44}

The reduction in the amount of CD44 on the membrane of B cells from Myo1g-deficient mice can be explained by defects in its recycling process. To test this, we evaluated different steps of the recycling process. The recruitment of CD44 to lipid rafts did not vary between WT and Myolg-deficient B lymphocytes (Figure 5A), we can observe the lipid rafts region in 6, 7, and 8 fractions. An impaired amount of lipid rafts in Myolg-deficient B lymphocytes was observed; this reduction can be explained by the reduced quantity of lipid rafts in the plasma membrane of activated B cells (Figure 4). We also treated B-lymphocytes with $\mathrm{M} \beta C D$ to destroy lipid rafts and then searched for CD44. We did not observe significant differences in the localization of CD44 between WT and Myolg-deficient B lymphocytes (Figure 5A, bottom). We next evaluated if HA-endocytosis by B lymphocytes from WT or Myolg-deficient was comparable. We detected similar internalization of $\mathrm{HA}$ in both groups (Figure 5B).

Continuing in this same way, we evaluate CD44-endocytosis in response to crosslinking, the following assay was developed. Surface proteins from B cells were biotinylated, and then 5-min capping with $\alpha$-CD44 was induced. The cells were trypsinized, and then treated with unlabeled streptavidin to quench extracellular proteins and recover only the intracellular label. The cells were then lysed and the biotinylated proteins were immunoprecipitated using streptavidin-agarose. Finally, the presence of biotinylated-CD44 was detected in the intracellular compartments. Under these conditions, we detected only internalized protein, because we "shave" the cell surface, furthermore, we treated B lymphocytes with unlabeled streptavidin; in these circumstances, all the cell surface proteins were "unlabeled," only biotinylated proteins inside the cell (because of the internalization) were "protected" and could be detected.

We observed similar endocytosis of CD44 in B cells from both WT and Myolg-deficient mice in response to CD44-crosslinking (Figure 5C). The same experiments were repeated after 10-min capping (Figure S8A in Supplementary Material); or at lower temperature (Figure S8B in Supplementary Material); or with colchicine treated B-lymphocytes (Figure S8C in Supplementary Material) (80-83). We did not observe differences in CD44internalization between WT and $\mathrm{Myolg}^{-/-} \mathrm{B}$ cells.

One important step in the recycling process is the association of GTPases (CDC42, RhoA, Rab5, and Rab11) with the recycling complex. During the recycling, GTPases change from an inactive to an active conformation (84). Accordingly, we evaluated the association of Myolg with GTPases. The results demonstrated the presence of several GTPases in the immunoprecipitates of Myolg (Figure 5D).

CD44 is involved in several processes such as adhesion, migration, and invasion. To perform these functions, CD44 must be internalized and recycled to the plasma membrane. This pathway involves GTPases such as Rab5, Rab4, Rab11, RhoA, and 

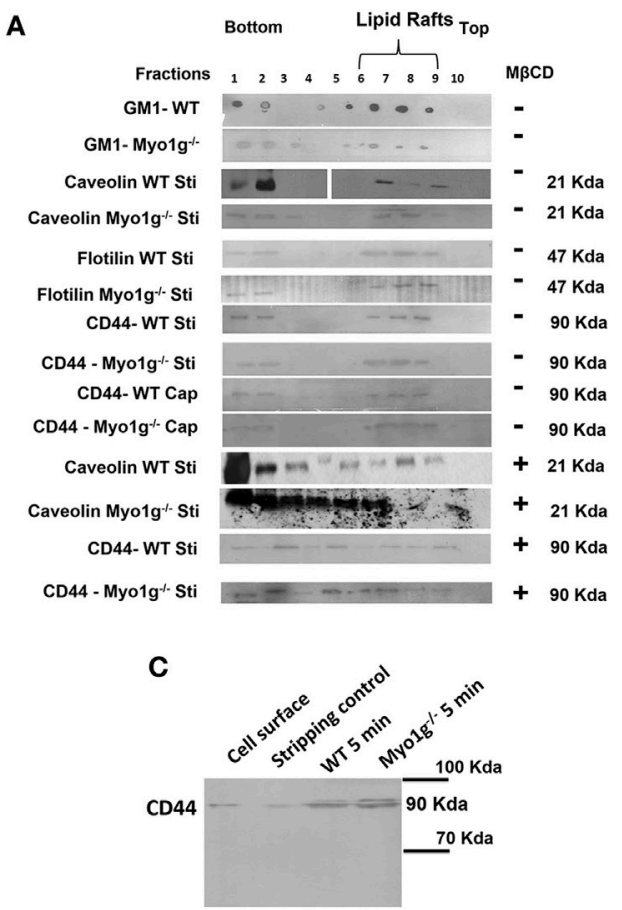

E

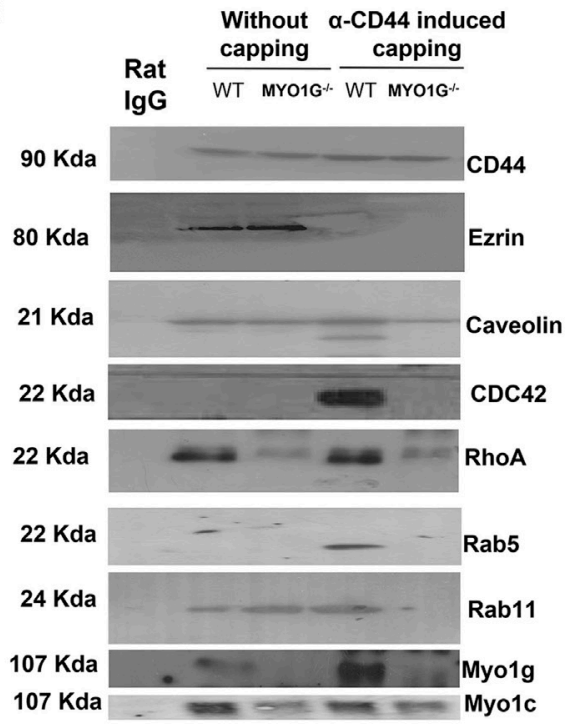

IP: CD44

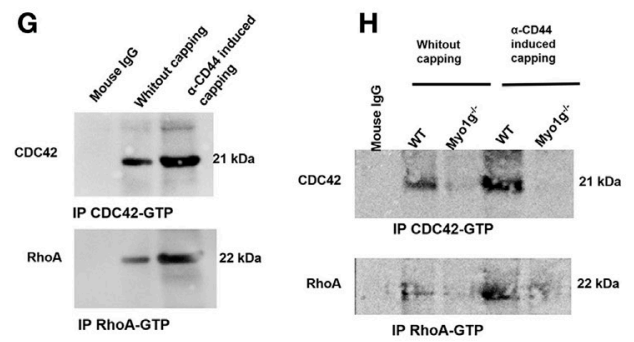

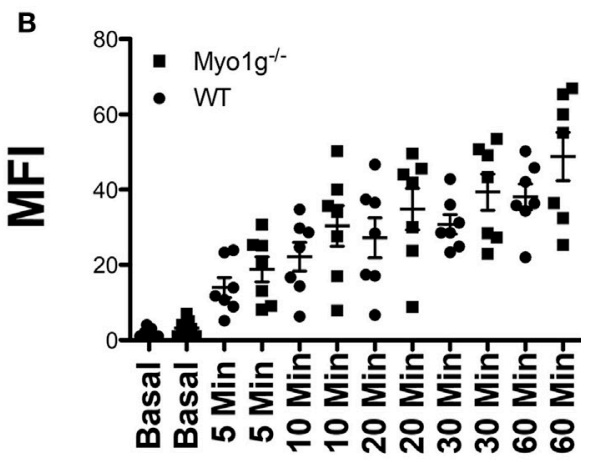

D

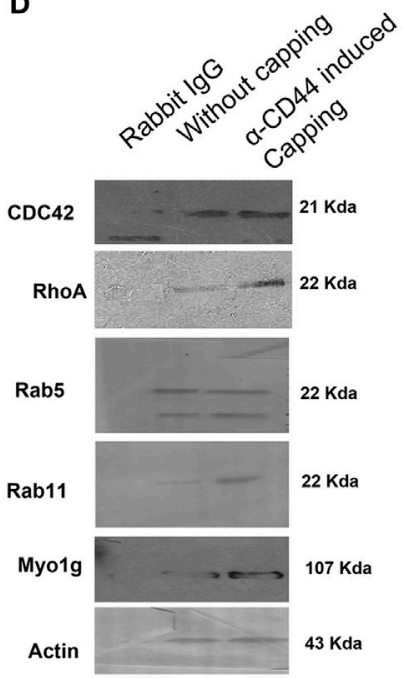

\section{IP: Myo1g}

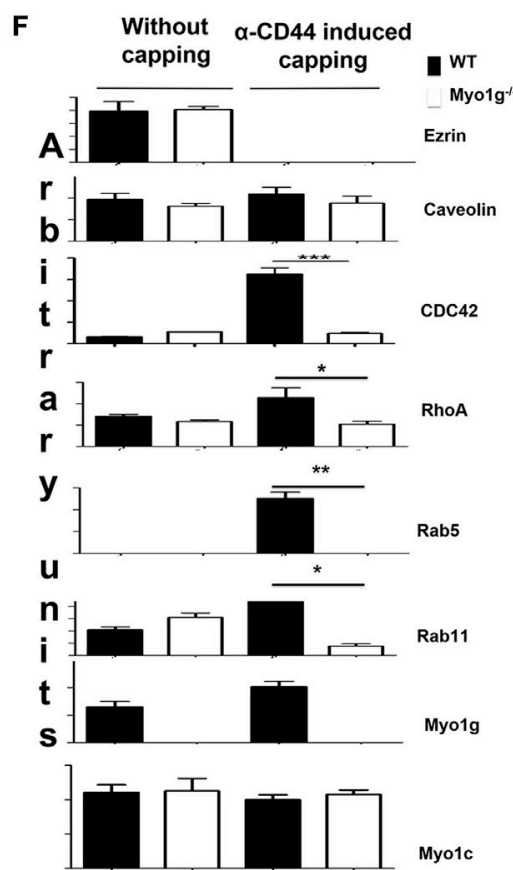




\section{FIGURE 5 | Continued}

The absence of Myo1g alters the recycling of CD44. (A) Western blot of CD44, caveolin, flotilin, GM1 in activated or cap-induced B cells from WT or Myo1gdeficient B cells, treated or not with $\mathrm{M} \beta \mathrm{CD}(n=3)$. (B) Resting B- lymphocytes were treated with FITC-hyaluronic acid $(\mathrm{HA})$ for $1 \mathrm{~h}$ at $4^{\circ} \mathrm{C}$ and were then incubated at $37^{\circ} \mathrm{C}$ for different time points. After incubation, the fluorescence was quenched by the addition of $0.5 \%$ trypan blue for $30 \mathrm{~s}$, and the cells were extensively washed with $1 \times$ phosphate-buffered saline. Finally, the cells were fixed and fluorescence was analyzed by flow cytometry. The graph shows the percentage of HA endocytosed by B-lymphocytes. The results are derived from the analysis of seven independent experiments and presented as mean \pm SD. (C) Immunodetection of intracellular CD44 in WT or Myo1 g ${ }^{-/}$activated B cells induced to cap with the NIMR8 mAb $(n=3)$. (D) Immunoprecipitation of Myo1g in activated B lymphocytes from WT mice, comparing cells with or without CD44-induced capping $(n=3)$. (E) Immunoprecipitation of CD44 from activated B cells from WT or Myo1g-deficient mice, comparing cells with or without CD44 capping $(n=3)$. (F) Densitometry analysis of GTPases associated with the CD44-recycling complex. Images were analyzed using the ImageJ software to obtain the values. One-way ANOVA test was used in this graph, values are mean $\pm \mathrm{SD}(n=3)\left({ }^{\star} P<0.05\right)\left({ }^{\star \star} P<0.01\right)$. (G) Immunoprecipitation of CDC42-GTP and RhoA-GTP in activated or $\alpha$-CD44-induced-capping B lymphocytes from WT mice ( $n=3)$. (H) Immunoprecipitation of CDC42-GTP and RhoA-GTP from activated B cells from WT or Myo1g-deficient mice, comparing cells with or without CD44 capping ( $n=3$ ).

CDC42, as well as the coating protein caveolin (84) in several steps of this recycling pathway.

To analyze the participation of Myolg in the recycling of CD44, immunoprecipitation assays using WT and Myolg-deficient B cells were performed. A first step involves the migration of CD44 to lipid rafts through association with caveolin, dissociation from ezrin, and recruitment of RhoA and CDC42 to lipid rafts. A second step is defined by the association of the endosome carrying CD44 with Rab5 (early endosome). The third step is the association of this vesicle with Rab11. We demonstrate that the migration of CD44 to lipid rafts was similar between WT and Myo1g-deficient B cells. In addition, recruitment of RhoA and CDC42 was reduced in Myolg-deficient B cells compared to WT cells. In agreement with this observation, the association of vesicles carrying CD44 with Rab5 was incomplete and there was no association with Rab11 (Figure 5E).

Myolc has been implicated in this recycling pathway (85); therefore, we tested for the presence of this motor protein in this complex, in the absence of Myolg. No differences in Myolc association were observed. To quantify the differences in the molecules associated with the CD44-recycling complex, a densitometry analysis was performed (Figure 5F). The activation of CDC42 and RhoA in response to CD44-crosslinking was also evaluated. We immunopreciptated RhoA and CDC42 under the conditions mentioned in Figures 5D,E, finding an increase in the activation of these GTPases (Figure 5G). In sharp contrast, we found an impaired activation of RhoA and CDC42 in Myolgdeficient B cells after CD44-crosslinking (Figure 5H).

In this same context, we performed staining for CD44, Myo1g, Rab5, Rab7, and Rab11 to validate the results mentioned above. We analyzed the cells $20 \mathrm{~min}$ after the NIMR8-crosslinking, we observed strong colocalization between Rab11, CD44, and Myo1g (Figure 6A); a more discreet interaction was observed with Rab5 (Figure 6B); however, we did not detect colocalization with Rab7 (Figure 6C). To further validate these data, the location of Rab5, Rab11, CD44, and Myo1g was evaluated, where these four cell molecules can be observed in the same pixels (Figure 6D). The profiles are shown in histograms next to figures, the lines indicates the location of cell molecules. Finally, the Pearson's coefficient (colocalization index) between these molecules is depicted in Figure 6E. These values allow us to infer a spatiotemporal organization of CD44-recycling.

The results indicate that Myolg plays a role in the output of lipid raft-associated proteins to the plasma membrane.
To further confirm these observations, splenic lymphocytes were biotinylated, and then the cells were incubated $10 \mathrm{~min}$ with NIM-R8 antibody to induce the capping of CD44. After capping, these cells were treated with trypsin to remove surface proteins (survival rate after trypsin treatment was always 90-95\%-data not shown). These trypsin-treated cells were further incubated to measure the rate of lipid raft recycling in B lymphocytes (using $\alpha-B 220$ antibody as generic marker to identify B cells). As shown in Figure 7A, the rate of endocytosis of these molecules was similar in both cell types; however, the exocytosis of CD44 (Figure 7B) and biotinylated proteins (Figure 7C) (in pre-gated $\mathrm{B} 220^{+} \mathrm{CD} 44^{+}$ and $\mathrm{B} 220^{+}$Streptavidin $^{+}$, respectively), was significantly lower in Myolg-deficient B cells compared to WT lymphocytes. This reduced velocity of raft recycling caused a dramatic accumulation of labeled protein inside the cell.

During spreading, recycling of CD44 is needed (86). To analyze how CD44 is relocated on the cell surface and how this affect spreading, the trypsin-treated cells, described above, were incubated for 2, 2.5, and $3 \mathrm{~h}$ and analyzed by their capacity to spread over CD44-coated coverslips. Cells in spreading have larger membrane-protrusions and elongated cell-morphology, contrasting with B-cells that did not spread, who have rounded morphology without visible protrusions (37). Although less Myolg-deficient B cells adhered to the coverslips, those that bound to the surface showed a reduced number of membraneextensions (observed though phalloidin-TRITC staining) at 2 and $2.5 \mathrm{~h}$. However, after $3 \mathrm{~h}, \mathrm{~B}$ cells belonging to Myo $1 \mathrm{~g}$-deficient mice produced membrane-protrusions like B cells from WT mice (Figure 8A). In these experiments, the area of the cells (Figure 8B), the shape factor (Figure 8C) as well as the number (Figure 8D), length (Figure 8E), and thickness (Figure S9A in Supplementary Material) of these membrane-projections were evaluated. Shape factor is a coefficient of the length and width of each given cell. Values closer to 1.0 indicated a more rounded morphology $(33,41,44,87)$.

The results showed a decrease in these parameters at 2 and $2.5 \mathrm{~h}$. However, we detected a trend toward recovery, like the WT phenotype, within $3 \mathrm{~h}$ of adhesion. Another important characteristic of these $\mathrm{B}$ cells was the presence of branched protrusions in WT B cells. Myolg-deficient B cells showed reduced percentage, numbers of ramifications by protrusion, and number of branched protrusions by cell (Figures S9B-D in Supplementary Material).

Like the spreading assay, when the incubation time for the capping assay was extended from 0.5 to $2 \mathrm{~h}$, a recovery 


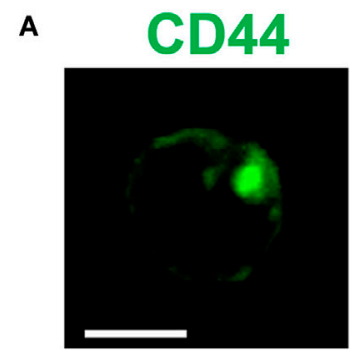

\section{BF}

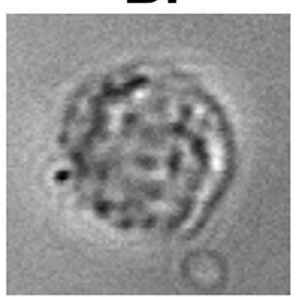

в $\quad$ CD44

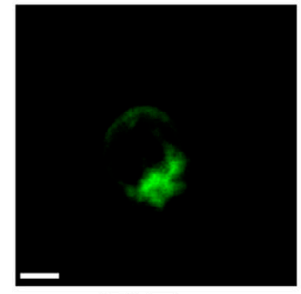

BF

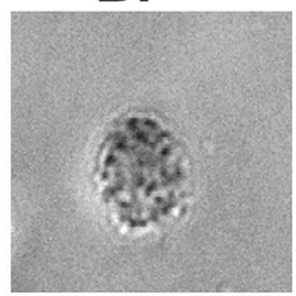

c

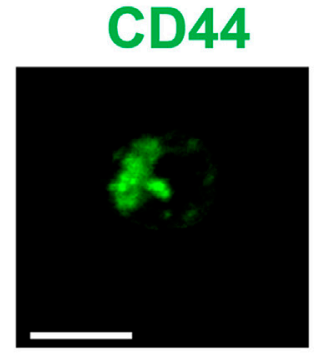

BF

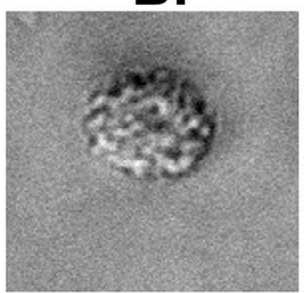

Rab11

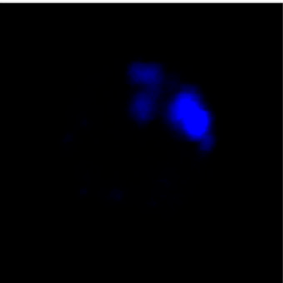

Merge

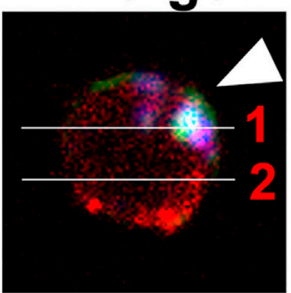

Rab5



Merge

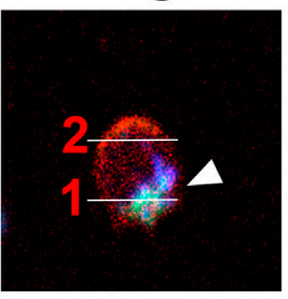

Myo1g

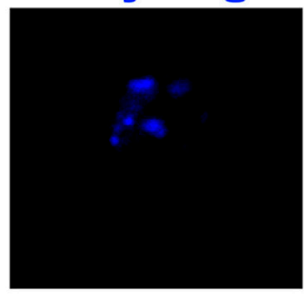

Merge

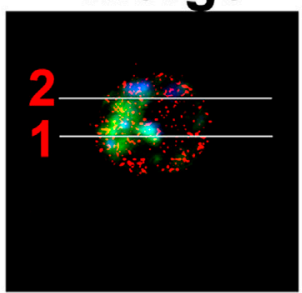

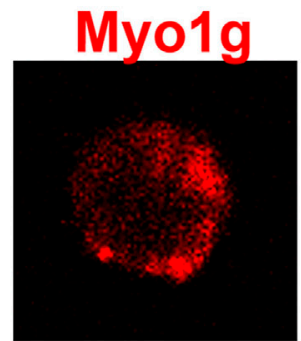

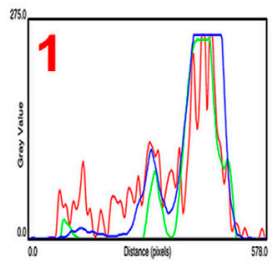

Merge
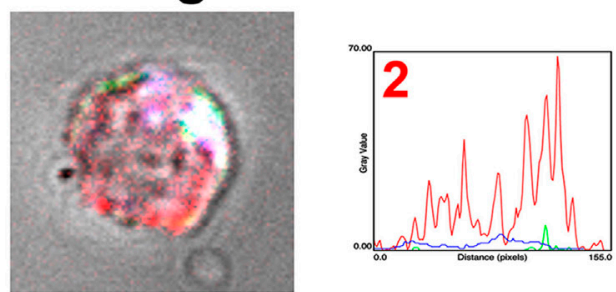

Myo1g

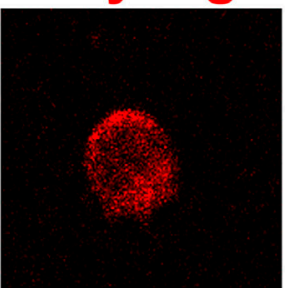

\section{Merge}
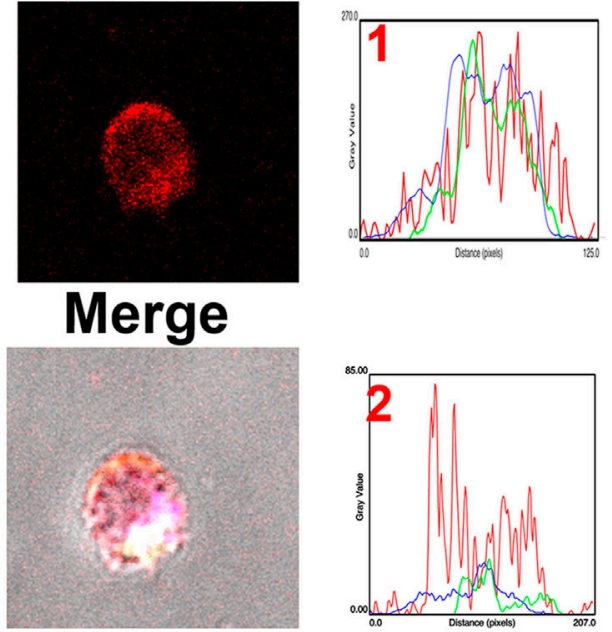

Rab7
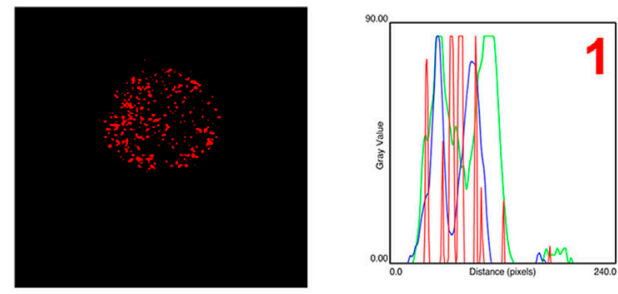

\section{Merge}
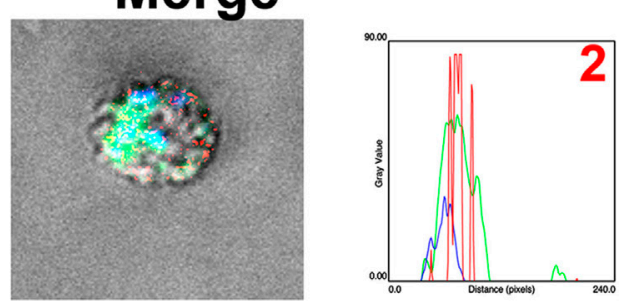


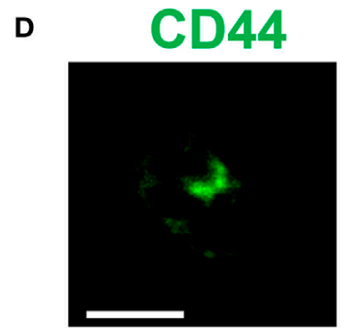

Rab5
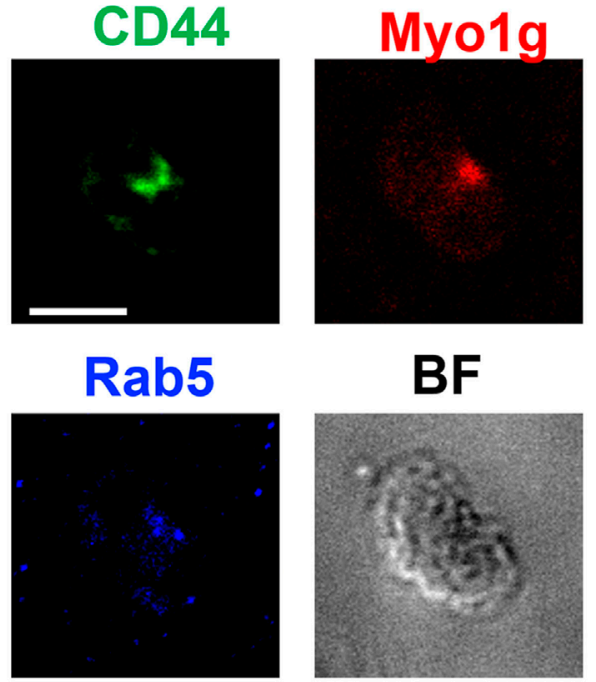

BF

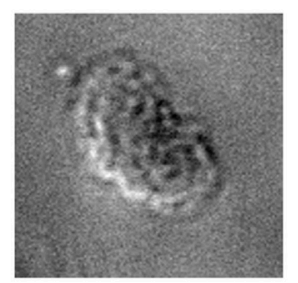

E

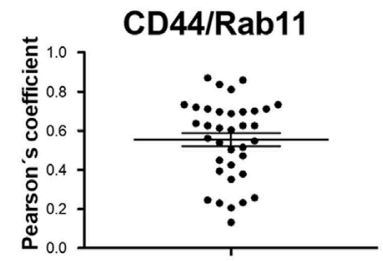

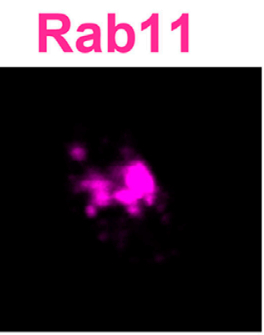

Merge
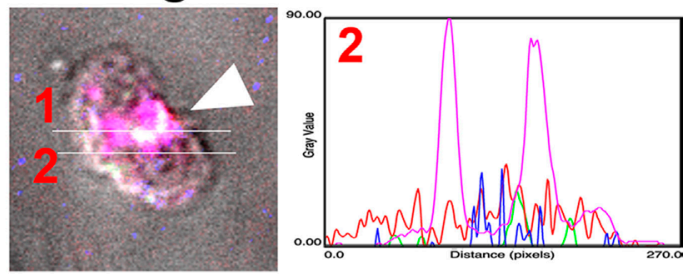

CD44/Rab5

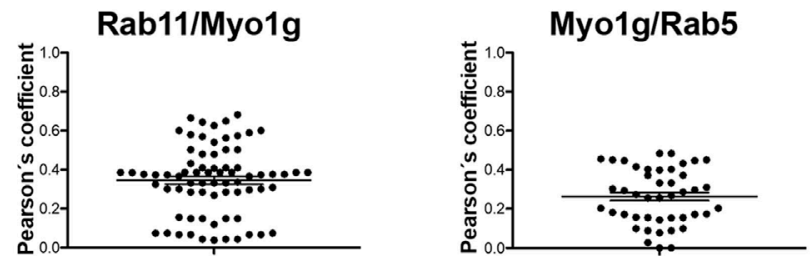

FIGURE 6 | Continued

Myo1g interacted with Rab5 and Rab11. Confocal images of LPS plus IL4-activated WT B cells and then, crosslinked with $\alpha$-CD44. The cells were stained with $\alpha$-CD44, $\alpha$-Rab5, $\alpha$-Rab7, $\alpha$-Rab11, and $\alpha$-Myo1g. Arrows illustrate the location of the molecules during CD44-recycling phenomena (scale bar $5 \mu$ m), (A) Rab11,

(B) Rab5, (C) Rab7, (D) Rab5 and Rab11. (E) Pearson's correlation coefficient between several molecules.

in the polarization of CD44 in Myo1g ${ }^{-/-}$B lymphocytes was observed (Figures S9E,F in Supplementary Material). Finally, CD44 polarization in B lymphocytes from $\mathrm{Myolg}^{-/-}$mice without trypsin-treatment (see above) and extended incubation $(1,1.5$, and $2 \mathrm{~h}$ ) also showed delayed polarization of CD44 (Figure 8F).

To confirm the contribution of Myo1g in CD44-recycling, Myo1g $\mathrm{g}^{-/-} \mathrm{B}$ cells were transfected with Full-Length Myolg coupled to GFP (Myolg-FL) or with an empty vector. We examined the percentage of Myo1 $\mathrm{g}^{-/-}$expressing Myo1g-FL (Figure S10A in Supplementary Material). Around $55-70 \%$ of cells were positive to GFP. We also verified the expression of Myolg via western blot, we observed the presence of Myolg in $\mathrm{Myolg}^{-/-} \mathrm{B}$ cells (Figure S10B in Supplementary Material).

In these reconstituted B-lymphocytes, we analyzed CD44expression, CD44-induced capping and spreading. As shown in Figures 9A,B, we observed the formation of CD44-cap structures in Myolg-reconstituted B-lymphocytes. CD44-expression was also restored to WT levels when Myolg expression was reestablished (Figures 9C,D). An increased number and size of membrane projections was also observed in Myolgreconstituted B-lymphocytes (Figure 9E). To further validate this result, we measured cell-area of these lymphocytes, the data illustrate a recovery in their area (Figure 9F). These data support the participation of Myo1g in the recycling of CD44, and its presence is needed to maintain membrane projections in B lymphocytes.

\section{Absence of Myo1g Affects CD44- Dependent Adhesion, Uptake of HA- Coated Beads, and Migration in B Lymphocytes}

As previously mentioned, CD44 is involved in adhesion, migration $(88,89)$, and phagocytosis (43), among other functions. Thus, CD44 adhesion of $\mathrm{Myolg}^{-/-}$B lymphocytes was evaluated. 


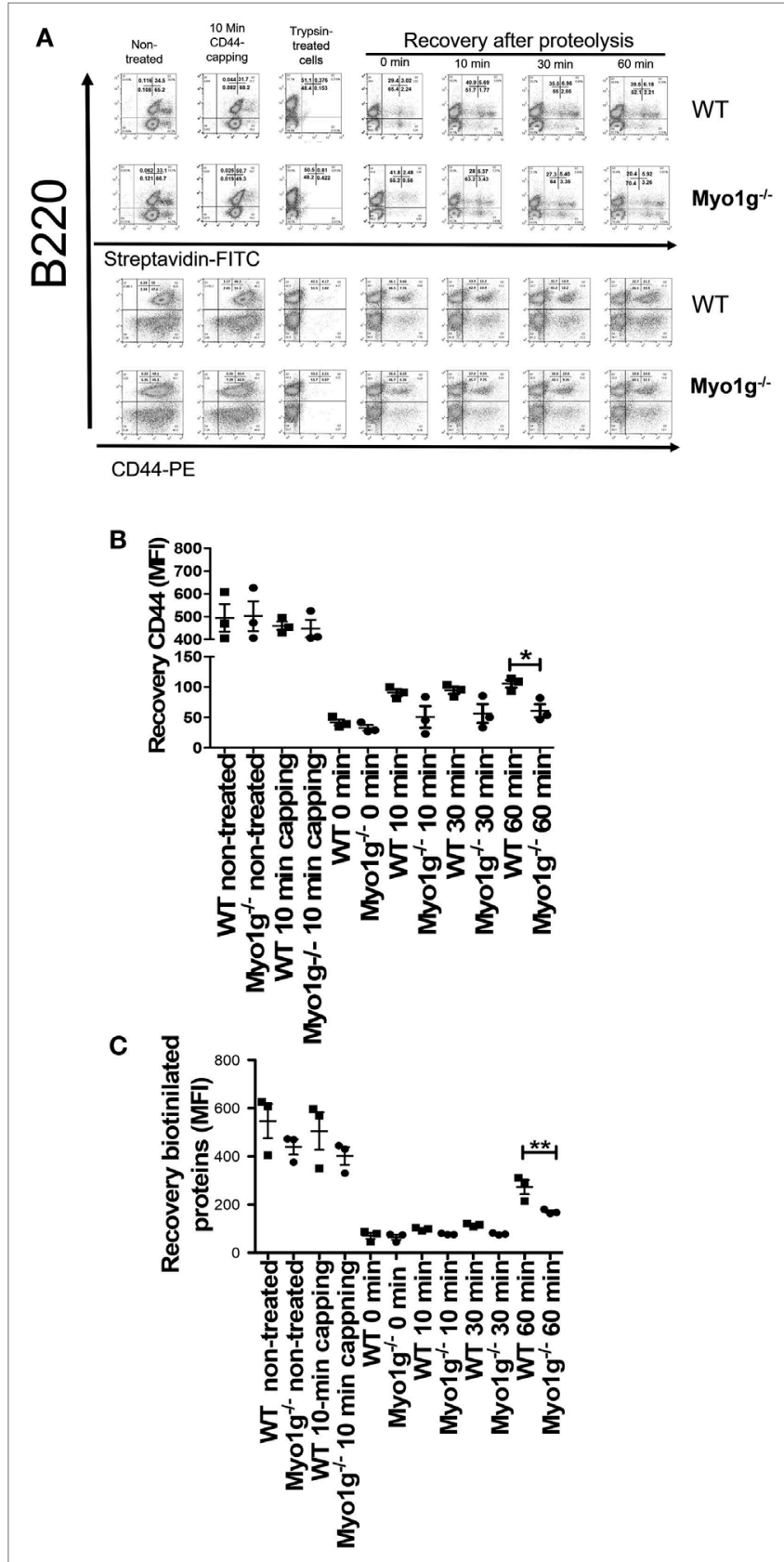

FIGURE 7 | The absence of Myo1g delays the recycling of CD44. (A) Kinetics of CD44-recycling in B lymphocytes from WT or Myo1g-deficient mice. MFI of CD44 (B) or biotinylated proteins (C) in B lymphocytes during the recycling process, One-way ANOVA tests were used in these experiments, values are mean $\pm \mathrm{SD}\left({ }^{\star} P<0.05,{ }^{\star \star} P<0.01\right)(n=3)$.

It was observed that Myo1 $\mathrm{g}^{-/-} \mathrm{B}$ cells adhered less efficiently than WT B cells to HA. To demonstrate specificity, we pretreated B lymphocytes with $\alpha-C D 44$ clone IM7 (who interferes with the CD44-HA interaction), this pretreatment altered the adhesion to HA of WT and Myo1 $\mathrm{g}^{-/-} \mathrm{B}$ cells. B cells from either Myo1 $\mathrm{g}^{-/-}$or WT B cells did not show defects in IgM-adhesion (Figure S11A in Supplementary Material).
CD44-dependent endocytosis was also evaluated. Thus, we treated micro-spheres with HA, then, these beads were incubated with B lymphocytes from WT or Myolg-deficient mice; in some experiments, B cells were pretreated with $\alpha$-CD44 clone IM7. The results indicated reduced uptake of HA-coated beads. The differences disappeared by IM7 pretreatment, indicating a CD44-dependent mechanism (Figure S11B in Supplementary Material).

CD44-dependent migration was then evaluated in more physiological settings, using transendothelial cell migration and in vivo homing assays. These methods are illustrated in Figures 10A,F, respectively. In some cases, we performed the same pretreatment with $\alpha$-CD 44 clone IM7 to evaluate the role of CD44 in this physiologic process. In the transendothelial migration assays, the Myolg-deficient B cells demonstrated reduced migration in response to a CXCL13 gradient, compared with WT B lymphocytes. Pretreatment with IM7 antibody reduced the migration of WT B cells (Figure 10B), demonstrating the role of CD44 in this process. Simultaneously, the number of cells per field, in the filter containing the endothelial monolayer, was quantified. Less $\mathrm{Myolg}^{-/-} \mathrm{B}$ cells adhered to the monolayer, and the adhesion was CD44-dependent as was shown by the inhibition observed with the IM7 antibody (Figure 10C). The experiments described above were performed using resting B cells. We, therefore, repeated these studies using LPS plus IL- 4 activated $\mathrm{B}$ cells, the results become like those observed with resting B cells (Figures 10D,E).

As described above, we then measured migration in vivo, by inoculating mixtures of CFSE-labeled B cells from WT or Myolg-deficient mice to a WT recipient mouse (iv route) and then, we quantified the migrating cells in spleen, lymph nodes, and peripheral blood (Figure 10F). The results obtained from these experiments showed a reduced number of Myolg-/ $B$ cells in the spleen and the lymph nodes. Pretreatment with $\alpha$-CD44 clone IM7, as shown in vitro, caused the reduction of recruitment to spleen and lymph nodes, with a corresponding greater proportion of $\mathrm{B}$ cells in the peripheral blood (Figure 10G). Taken together, these results indicate that Myolg-deficient B cells have an impaired ability to cross the endothelial barrier.

The recycling of CD44 and lipid rafts is crucial in diverse cell processes, for this reason, we used primaquine-, chloroquine-, and monensin-treated B lymphocytes to examine: transendothelial migration (Figure 10H); 2D migration under CXCL12 and CXCL13 (Figures S12A-C in Supplementary Material); spreading (Supplementary Figures S12D,E in Supplementary Material); or surface expression of CD44 after HA treatment (Figure S12F in Supplementary Material). We registered an impaired transendothelial migration in recycling by all the inhibitors used in this assay (Figure 10H). Likewise, we observed a reduction in the speed, accumulated and Euclidian distance and straightness by the drugs (Figures S12A-C in Supplementary Material). We also detected the absence of membrane protrusions under these conditions (Figures S12D,E in Supplementary Material). Finally, the presence of CD44 on the surface of primaquine-treated cells was reduced (Figure S12F in Supplementary Material). To further corroborate these results, we evaluated the location of CD44, 


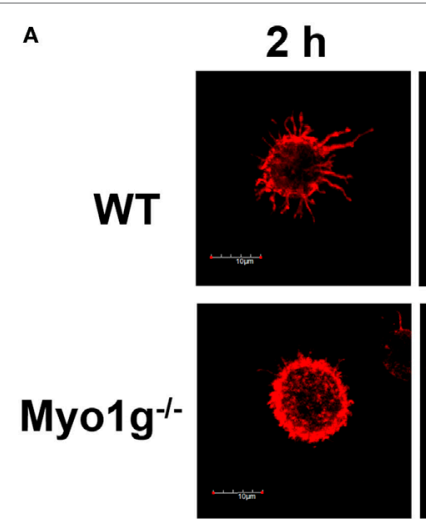

B

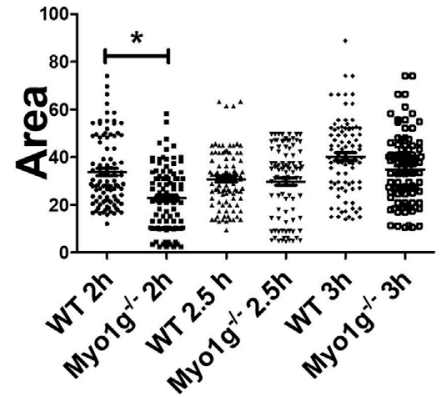

E
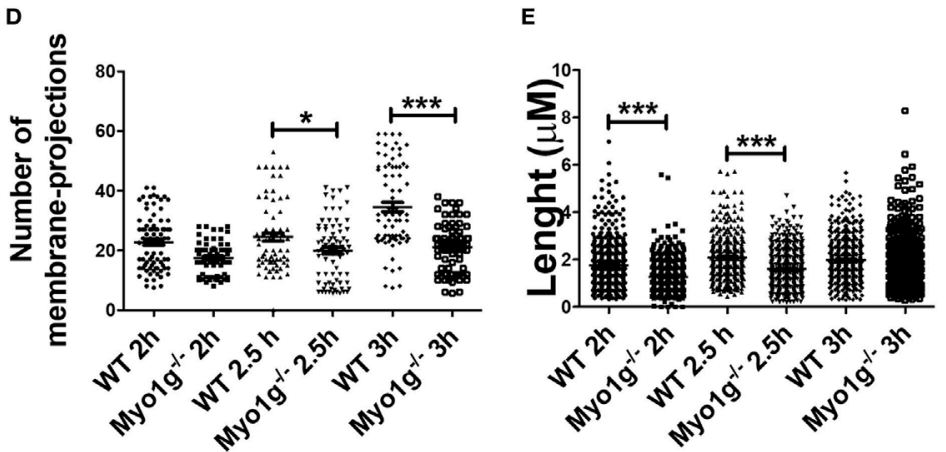

$3 \mathrm{~h}$
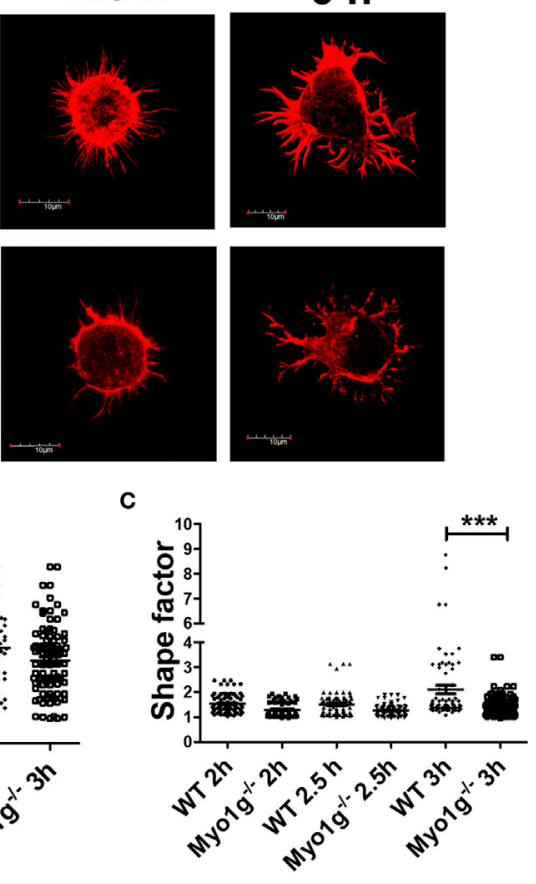

FIGURE 8 | The absence of Myo1g delays the formation of membrane-protrusions in B lymphocytes. (A) Confocal images of activated B cells from WT or Myo1g-deficient mice. B lymphocytes with spread morphology were evaluated for (B) area, (C) shape, (D) number of projections, and (E) the length of these projections after 2, 2.5, and $3 \mathrm{~h}$. A total of 100 cells, in three independent experiments, were analyzed in each group. (F) Percentage of cells with CD44-capping after 1, 1.5, and $2 \mathrm{~h}$. Images of randomly selected files were taken and the percentage of B lymphocytes with capping was recorded ( 70 cells were analyzed in 3 independent experiments, a total of 200 cells per data set are presented). One-way ANOVA tests were used in these experiments, values are mean \pm SD $\left({ }^{\star} P<0.05\right.$, $\left.{ }^{\star \star} P<0.01,{ }^{* \star *} P<0.001\right)$

Myo1g, Rab5, and Rab11 in migrating B lymphocytes. As it can be seen in Figure 10I, we found a spatiotemporal organization of these four molecules in migratory cells. As a whole, these results support a model of interaction between these four molecules during migration.

\section{DISCUSSION}

In this study, we established that Myolg drives the mobilization of CD44. B cells lacking Myolg revealed defective mobilization of CD44 and lipid rafts. Collectively, our data demonstrate a role for Myolg in the traffic of lipid raftdependent molecules.
Confocal microscopy studies showed that the capping of CD44 in resting B cells was unchanged in the absence of Myolg. This suggests that Myolg is not required for the mobilization of this protein under steady-state conditions. Alternatively, Myolg may be redundant with other proteins, including class I myosins (Myolc or Myole). In contrast, LPS plus IL4-activated B cells demonstrated impaired CD44 polarization. This is likely due to ineffective CD44 mobilization inside the cell, which may not be completely compensated by Myo1c or Myo1e. These data suggest an important role for Myo1g in the traffic of CD44. Previous studies have shown the participation of Myolc in the traffic of CD55, Glut4, and VEFGR2 in HeLa cells (85), adipocytes (90), and endothelial cells (91), respectively. Similarly, this study 


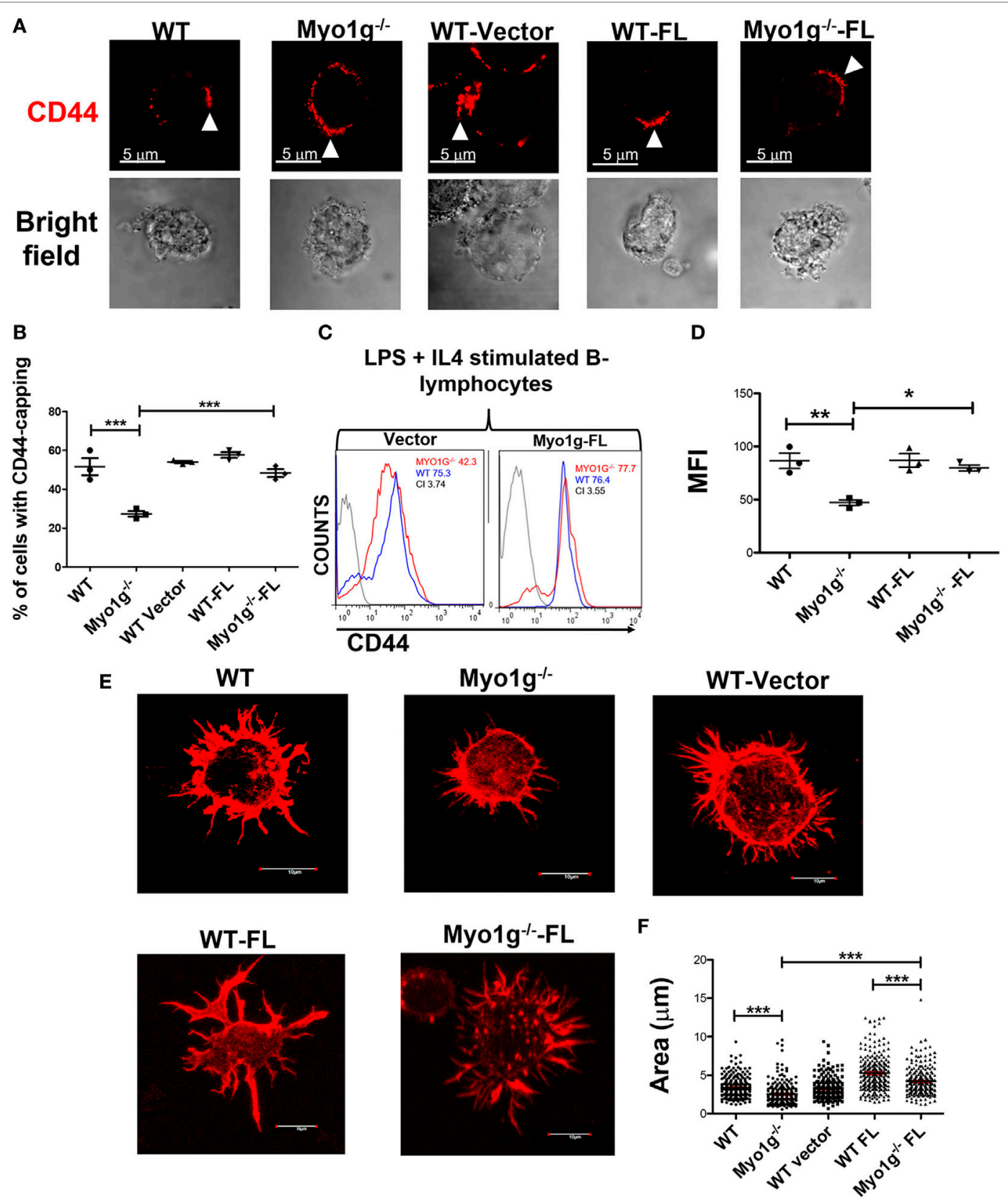

FIGURE 9 | Transfection with full-length Myo1g rescue CD44-dependent capping and spreading in Myo1g-deficient B-cells. (A) Confocal images of LPS plus IL4-activated B cells from WT, Myo1g ${ }^{-/}$, WT, or Myo1g $\mathrm{g}^{-/}$transfected with an empty vector or Myo1g-FL. Arrows illustrate the localization of CD44 in B lymphocytes (scale bar $5 \mu \mathrm{m}$ ). (B) Percentage of cells with CD44-capping. Images of randomly selected files were taken and the percentage of B lymphocytes with capping was calculated. A total of 200 cells per data set from three independent experiment were analyzed. One-way ANOVA test was used in these experiments, values are mean $\pm \mathrm{SD}\left({ }^{\star \star \star} P<0.001\right)(n=3)$. (C) Representative expression of CD44 in LPS plus IL4-activated B cells transfected or not with Myo1g-FL from WT or Myo1g-deficient B lymphocytes, the graph shows the expression of CD44 in B lymphocytes (10,000 events in a gate of B220 + B cells). (D) Expression of CD44 in LPS plus IL4-activated B cells transfected or not with Myo1g-FL from WT or Myo1g-deficient B lymphocytes. One-way ANOVA test was used in these experiments, values are mean $\pm \mathrm{SD}\left({ }^{\star} P<0.05,{ }^{*} P<0.01\right)(n=3)$. (E) Confocal images of activated B cells from WT or Myo1g-deficient mice over NIMR8. (F) The area of spread B lymphocytes was evaluated, a total of 150 cells per data set from three independent experiments were analyzed. One-way ANOVA test was used in these experiments, values are mean $\pm \mathrm{SD}\left({ }^{* \star *} P<0.001\right)$

demonstrates a role for Myo1g during CD44 translocation in activated B cells.

During cell migration, the role of regulators of actin dynamics, including actin bundles and capping proteins, are expected to play a critical role in controlling the architecture and dynamics of the actin meshwork that propels non-adhesive B cell migration. The deficiency in the polarization of CD44 in Myolg-deficient $\mathrm{B}$ cells affected cell migration. Consistent with a previous study 

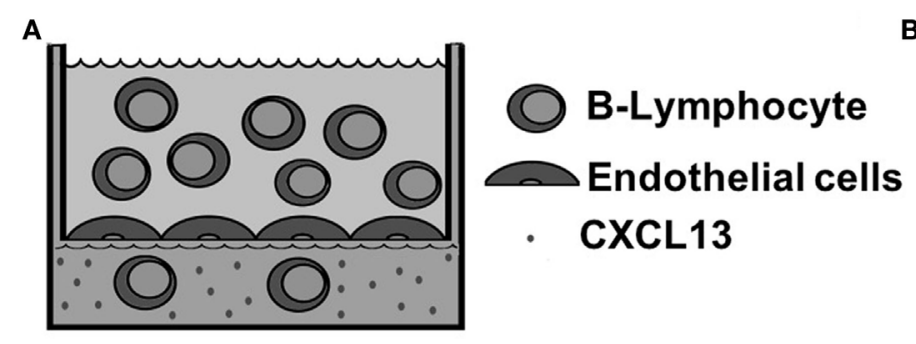

B

C

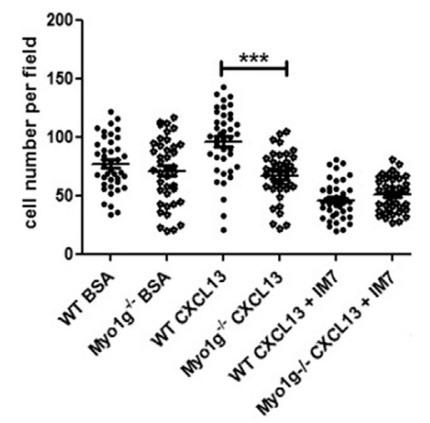

D

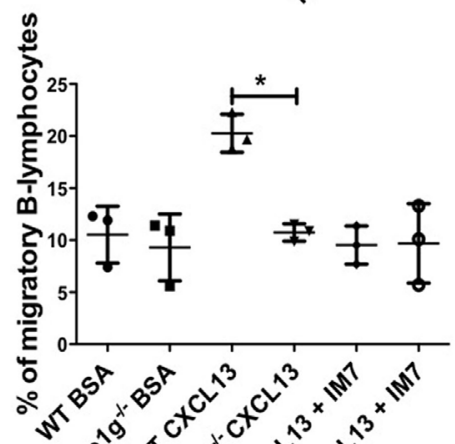

E

F
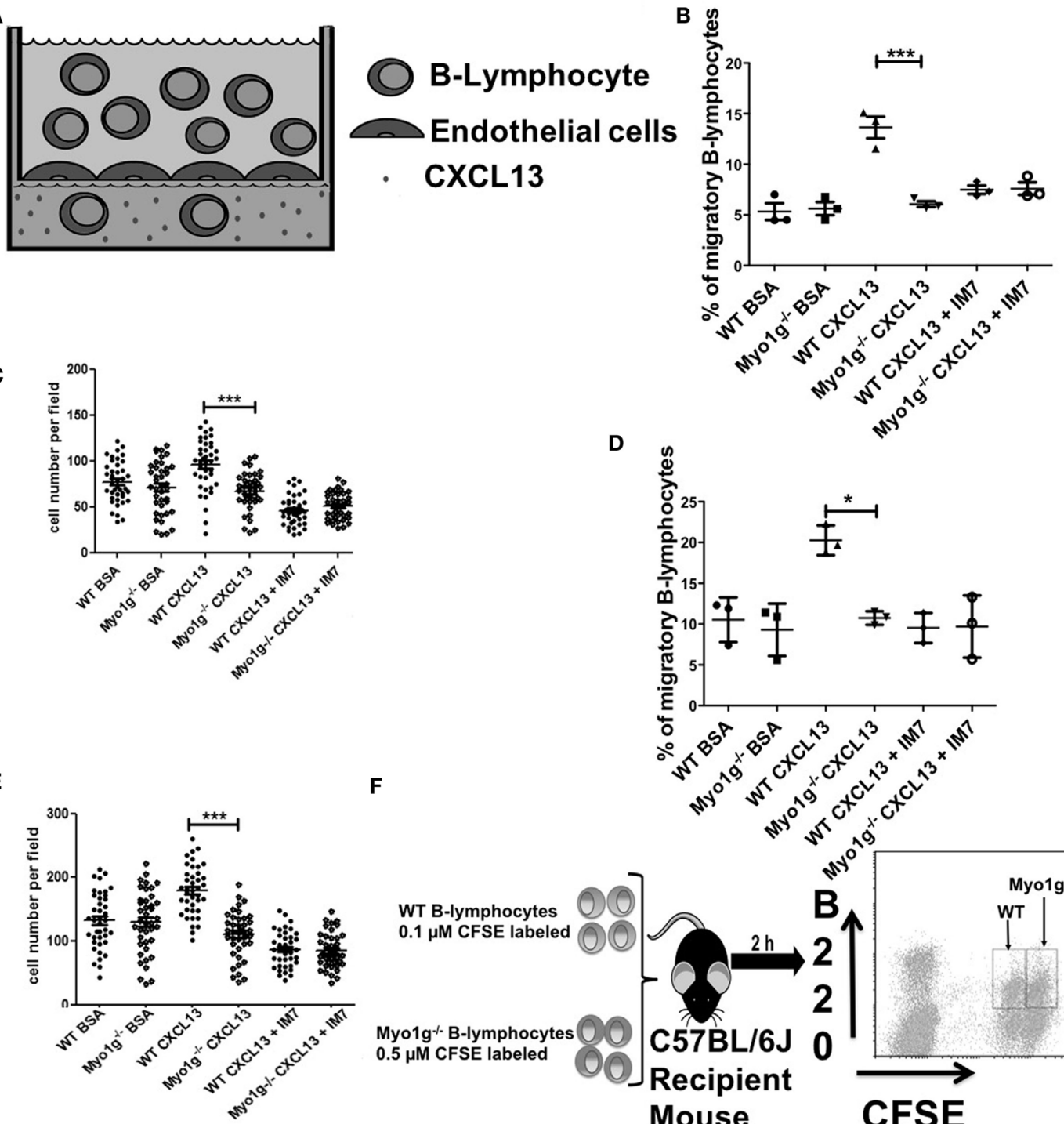

G

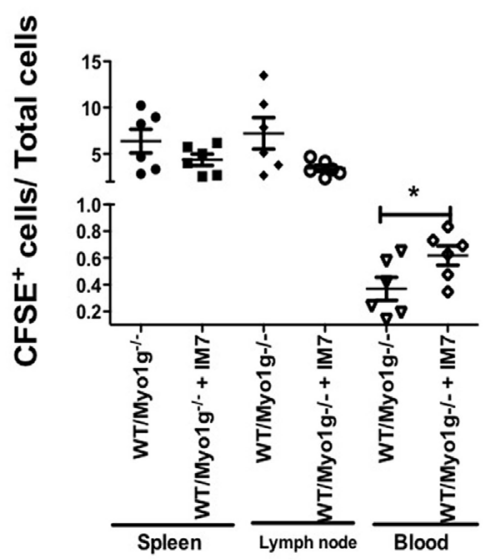

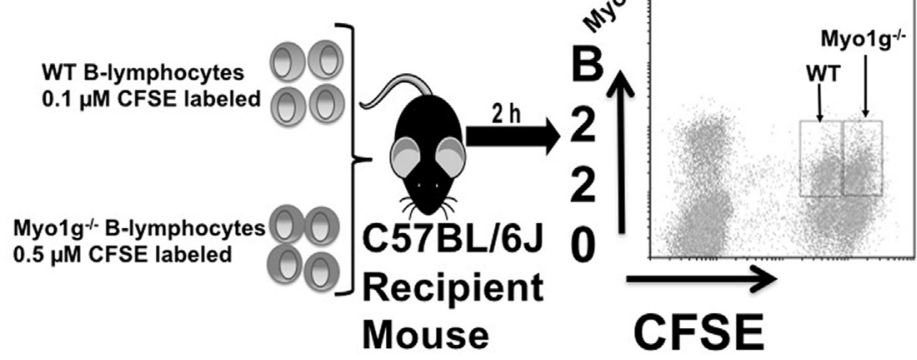

H

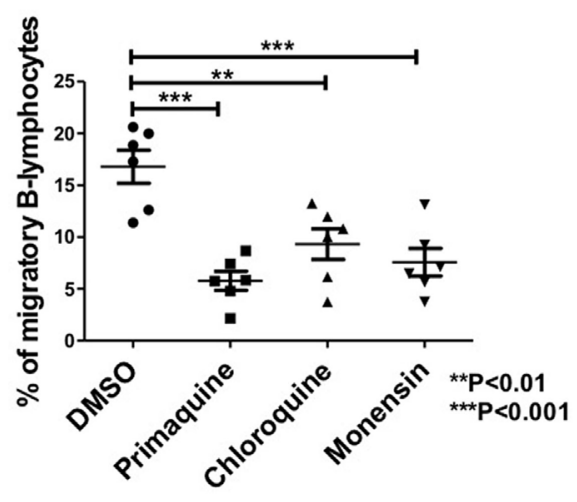

FIGURE 10 | Continued 


\section{I}

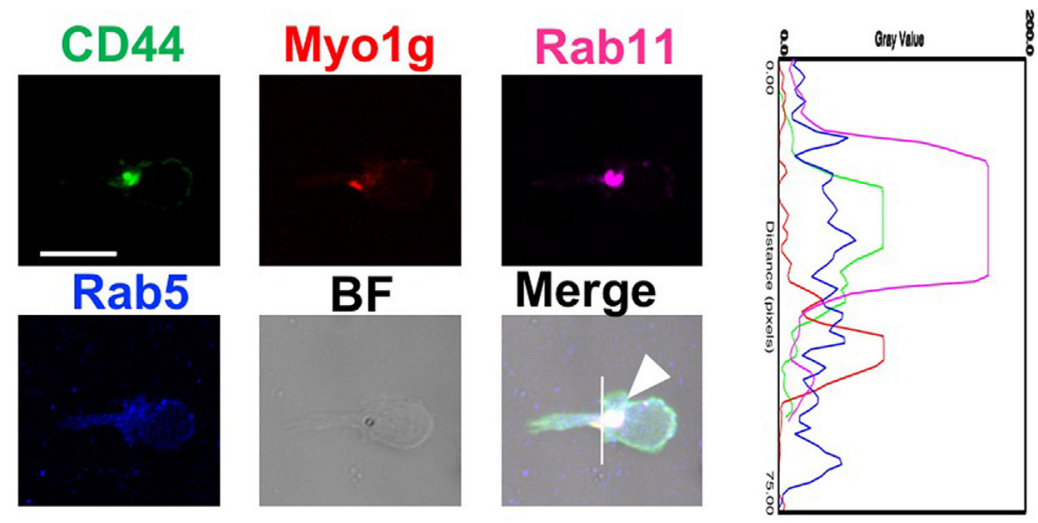

FIGURE 10 | Continued

Myo1g deficiency affects the migration of B lymphocytes. (A) Scheme of transendothelial migration where $4 \times 10^{5} \mathrm{~B}$ cells were placed in the upper compartment. (B,C) Analysis from resting WT or Myo1g-deficient B-lymphocytes. (D,E) Analysis of LPS plus IL-4 activated WT or Myo1g-deficient B lymphocytes. (B,E) Show the CXCL13-induced migration of B cells. (C,E) Percentage of migratory B cells that crossed the endothelial barrier. (F) Scheme of in vivo homing assay one-way ANOVA tests were used in these experiments, values are mean $\pm \mathrm{SD}\left({ }^{\star} P<0.05\right.$, $\left.{ }^{\star \star \star} P<0.001\right)(n=3)$. (G) $1 \times 10^{7}$ cells were transferred to recipient mice, the graph illustrates B cell recovery (CFSE ${ }^{+}$) percentage (WT/Myo1 ${ }^{-/-}$) from spleen, lymphatic nodes, and blood from Myo1 $\mathrm{g}^{-/-}$and WT mice. Data are mean \pm SD from three mice per assay in three independent experiments. One-way ANOVA test was used in these experiments, values are mean $\pm \mathrm{SD}\left({ }^{\star} P<0.05\right)(n=6)$.

(H) $4 \times 10^{5}$ resting B lymphocytes treated with vehicle, primaquine, chloroquine, or monensin were placed in the upper compartment during transendothelial transmigration. (I) Resting B-cells were placed on fibronectin-covered coverslips for 30 min, after that, the cells were treated with CXCL13 and incubated for 20 min, and then fixed and stained with antibodies for Rab5, Rab11, Myo1g, and CD44 for 20 min; the arrows indicate the location of these molecules in migratory B cells. The cells were then analyzed by confocal microscopy, scale bar $5 \mu \mathrm{m}$.

from our group, $\mathrm{Myolg}^{-/-} \mathrm{B}$ cells demonstrated slower migration trajectories than WT B cells (33). One possible cause for the reduced mobility of Myolg-deficient B cells is the delay in the traffic of adhesion molecules, which includes CD44. Thus, the deficiency of Myolg affects the traffic of these molecules. The entry of CD44 and integrins into cholesterol and glycosphingolipidrich domains was suggested as a mechanism of cell migration initiation since adhesion molecules and lipid rafts carry caveolin, thus enabling initiation of the recycling process. Moreover, cytoskeletal proteins and GTPases are simultaneously recruited to these recycling vesicles.

Previous biochemical and ultrastructural studies have demonstrated that CD44 is present in both raft and non-raft regions of cell membranes, similar to the motor protein Myolg in B cells (33).

The loss of function of Myo1g significantly delayed CD44cell spreading and plasma membrane delivery of raft-associated molecules in B cells. Expression of Myo1g aided the localization of lipid rafts in LPS plus IL4 activated B cells. This is consistent with observations by Bransdtatter et al. in 2012, showing that when Myolc is overexpressed, the expression of several markers of lipid rafts, such as CD55 and CD59, increases in the plasma membrane (85).

CD44 is dynamic, and its levels are maintained by internalization, recycling, and delivery to the plasma membrane. We have previously shown that in B cells, Myolg and GM1 co-localize at the plasma membrane (33). LPS plus IL4 stimulated B cells internalize and recycle CD44. This is also seen in Myo1g-deficient $\mathrm{B}$ cells, but there, the recycling process is not as efficient, leading to increased accumulation of CD44 inside the cell with consequent reduction in surface expression. The decrease in CD44 may affect formation of the immunological synapse in B cells as has been observed in T cells where the deficiency of CD44 affected formation of the immunological synapse between $\mathrm{T}$ cells and dendritic cells (92).

CD44 is mobilized to caveolae and is subsequently endocytosed $(84,93)$. Caveolae is a specialized structure that contains various associated molecules or microdomains such as lipid rafts $(84,94)$. CD44 has been found in these membrane microdomains $(93,95,96)$, with various roles in cell adhesion and migration (96). The composition, plasticity, and surface area of the plasma membrane is controlled by specialized endocytic recycling pathways, which maintain the balance between the endocytosis and exocytosis of specific proteins and lipids. Cargo proteins associated with lipid raft membranes are internalized by clathrin-independent endocytosis. However, the molecular determinants that regulate intracellular trafficking in this pathway have yet to be established (97).

We also observed that deficiency of Myolg affects the expression of lipid rafts on the surface of B cells. Interestingly, an association of Myo1g with lipid raft microdomains was first indicated by proteomics studies, which identified this myosin in purified lipid raft fractions isolated from B cells (98). The decrease in lipid rafts may affect the clustering of signaling molecules, with consequences for several process such as cell migration (99), BCR signaling (100), and dissociation of the CD3-CD8 complex in T cells (101). In fact, disruption of lipid rafts by nystatin and methyl- $\beta$-cyclodextrin affects the capping of IgM (102). A recent study demonstrated the presence of Myolg in a complex of cytosolic proteins, which include the GTPase RalA and the GTPase-activating protein srGAP2 (34). RalA has been associated with the exocytosis of integrins in mouse embryonic fibroblasts (7), and srGAP2 has been linked to migration and adhesion of neuronal cells (103). 
In the same context, adhesion molecules can activate the GTPase RalA and RalA-specific GEF. This GTPase can interact with the exocyst subunit Sec5. This subunit is required for cell spreading and raft exocytosis after cell adhesion. Downregulation of sec5 produces a reduction in cell spreading and cell adhesion (104). The interaction between the exocyst complex and the GTPase CDC42 is necessary for polarized secretion in yeast (104). This phenomenon has been linked to srGAP2 by through the inactivation of CDC42 in neuronal cells during cell migration (105). The presence of srGAP2 at the phagocytic cup in HEK293T cells has also been described (105). These observations are consistent with our previously published study in which the presence of Myolg was described in those sites (105), as well as with results from this study showing that Myolg actively participates in the recycling process of CD44. We believe that part of the defects in the recycling process of CD44 in the Myolg-deficient B cells can be attributed to the signaling molecules arriving at different times, because we did not detect major defects in the function of these cells. We are currently working to determine the mechanisms of this delay, but we believe that a delay in assembling this molecular complex may represent the best explanation for our observations.

Taken together, these findings demonstrate the defects in CD44-dependent functions in Myolg-deficient B cells. We observed reduction in all the functions examined (migration, adhesion, and phagocytosis). Our results correlate with the work of Cairns et al. (106) in which the authors observed an impaired clearance of apoptotic neutrophils by monocytes with reduced expression of CD44 (106), defective migration of CD44 KO fibroblasts after treatment with TGF- $\beta$ (107), or through the use of $\alpha$-CD44 antibodies, which block leukocyte migration in the skin (108). This study shows that Myolg is a predominant regulator of CD44 recycling in B cells and is important in CD44dependent cell functions.

\section{REFERENCES}

1. Madri JA, Graesser D. Cell migration in the immune system: the evolving inter-related roles of adhesion molecules and proteinases. Dev Immunol (2000) 7:103-16. doi:10.1155/2000/79045

2. Ridley AJ, Schwartz MA, Burridge K, Firtel RA, Ginsberg MH, Borisy G, et al. Cell migration: integrating signals from front to back. Science (2003) 302:1704-9. doi:10.1126/science.1092053

3. Simons K, Gerl MJ. Revitalizing membrane rafts: new tools and insights. Nat Rev Mol Cell Biol (2010) 11:688-99. doi:10.1038/nrm2977

4. Simons K, Toomre D. Lipid rafts and signal transduction. Nat Rev Mol Cell Biol (2000) 1:31-9. doi:10.1038/35036052

5. Urade R, Hayashi Y, Kito M. Endosomes differ from plasma membranes in the phospholipid molecular species composition. Biochim Biophys Acta (1988) 946:151-63. doi:10.1016/0005-2736(88)90468-3

6. Pozo D, Delgado M. The many faces of VIP in neuroimmunology: a cytokine rather a neuropeptide? FASEB J (2004) 18:1325-34. doi:10.1096/ fj.03-1440hyp

7. Balasubramanian N, Meier JA, Scott DW, Norambuena A, White MA, Schwartz MA. RalA-exocyst complex regulates integrin-dependent membrane raft exocytosis and growth signaling. Curr Biol (2010) 20:75-9. doi:10.1016/j.cub.2009.11.016

8. Okamoto T, Schlegel A, Scherer PE, Lisanti MP. Caveolins, a family of scaffolding proteins for organizing "preassembled signaling complexes" at

\section{ETHICS STATEMENT}

The mice were produced at the Centro de Investigación y de Estudios Avanzados (Mexico City, Mexico) animal facility. The Animal Care and Use Committee of Centro de Investigación y de Estudios Avanzados approved all experiments.

\section{AUTHOR CONTRIBUTIONS}

OL-O designed and performed the experiments; and wrote the paper. LS-A designed the experiments, supervised the work, and wrote the paper.

\section{ACKNOWLEDGMENTS}

We thank Dr. Steve Shaw from NCI, NIH for providing $M y o 1 g^{-1-}$ mice, Dr. Héctor Romero-Ramírez for his technical advice at different stages of this work, Dr. Michael Schnoor and MSC Alexander Garcia-Ponce for providing the Mlec cell line, M. V. Z. Ricardo Gaxiola Centeno and Tec. Victor Manuel García Gómez for their excellent technical assistance in the animal facility. Dr. Eduardo Salinas-Stefanon, Dr. Jaime Mas-Oliva, Dr. Ana Cecilia Zazueta-Mendizábal, Dr. Laura Berron-Ruiz, Dr. Genaro PatiñoLópez, and Dr. José Moreno for providing different reagents.

\section{FUNDING}

This work was supported by CONACyT (Grant 255053). OL-O was supported by fellowship 219624 from CONACyT.

\section{SUPPLEMENTARY MATERIAL}

The Supplementary Material for this article can be found online at http://www.frontiersin.org/article/10.3389/fimmu.2017.01731/ full\#supplementary-material.

the plasma membrane. J Biol Chem (1998) 273:5419-22. doi:10.1074/jbc 273.10.5419

9. Wang C, Yoo Y, Fan H, Kim E, Guan KL, Guan JL. Regulation of Integrin beta 1 recycling to lipid rafts by Rabla to promote cell migration. J Biol Chem (2010) 285:29398-405. doi:10.1074/jbc.M110.141440

10. Anderson RG, Kamen BA, Rothberg KG, Lacey SW. Potocytosis: sequestration and transport of small molecules by caveolae. Science (1992) 255:410-1. doi:10.1126/science.1310359

11. Fabbri M, Di Meglio S, Gagliani MC, Consonni E, Molteni R, Bender JR, et al. Dynamic partitioning into lipid rafts controls the endo-exocytic cycle of the alphaL/beta2 integrin, LFA-1, during leukocyte chemotaxis. Mol Biol Cell (2005) 16:5793-803. doi:10.1091/mbc.E05-05-0413

12. Knorr R, Karacsonyi C, Lindner R. Endocytosis of MHC molecules by distinct membrane rafts. JCell Sci (2009) 122:1584-94. doi:10.1242/jcs. 039727

13. Smart EJ, Ying Y, Donzell WC, Anderson RG. A role for caveolin in transport of cholesterol from endoplasmic reticulum to plasma membrane.J Biol Chem (1996) 271:29427-35. doi:10.1074/jbc.271.46.29427

14. Thankamony SP, Knudson W. Acylation of CD44 and its association with lipid rafts are required for receptor and hyaluronan endocytosis. J Biol Chem (2006) 281:34601-9. doi:10.1074/jbc.M601530200

15. Lesley J, Hyman R, Kincade PW. CD44 and its interaction with extracellular matrix. Adv Immunol (1993) 54:271-335. doi:10.1016/ S0065-2776(08)60537-4 
16. Legg JW, Isacke CM. Identification and functional analysis of the ezrin-binding site in the hyaluronan receptor, CD44. Curr Biol (1998) 8:705-8. doi:10.1016/S0960-9822(98)70277-5

17. Zohar R, Suzuki N, Suzuki K, Arora P, Glogauer M, McCulloch CA, et al. Intracellular osteopontin is an integral component of the CD44-ERM complex involved in cell migration. JCell Physiol (2000) 184:118-30. doi:10.1002/(SICI)1097-4652(200007)184:1<118::AID-JCP13>3.0.CO;2-Y

18. Bartolazzi A, Peach R, Aruffo A, Stamenkovic I. Interaction between CD44 and hyaluronate is directly implicated in the regulation of tumor development. J Exp Med (1994) 180:53-66. doi:10.1084/jem.180.1.53

19. Borland G, Ross JA, Guy K. Forms and functions of CD44. Immunology (1998) 93:139-48. doi:10.1046/j.1365-2567.1998.00431.x

20. Schmits R, Filmus J, Gerwin N, Senaldi G, Kiefer F, Kundig T, et al. CD44 regulates hematopoietic progenitor distribution, granuloma formation, and tumorigenicity. Blood (1997) 90:2217-33.

21. Protin U, Schweighoffer T, Jochum W, Hilberg F. CD44-deficient mice develop normally with changes in subpopulations and recirculation of lymphocyte subsets. J Immunol (1999) 163:4917-23.

22. Orian-Rousseau V, Ponta H. Perspectives of CD44 targeting therapies. Arch Toxicol (2015) 89:3-14. doi:10.1007/s00204-014-1424-2

23. Radhakrishna H, Al-Awar O, Khachikian Z, Donaldson JG. ARF6 requirement for Rac ruffling suggests a role for membrane trafficking in cortical actin rearrangements. J Cell Sci (1999) 112(Pt 6):855-66.

24. Bement WM, Mooseker MS. Molecular motors. Keeping out the rain. Nature (1993) 365:785-6. doi:10.1038/365785a0

25. Rayment I, Rypniewski WR, Schmidt-Base K, Smith R, Tomchick DR, Benning MM, et al. Three-dimensional structure of myosin subfragment-1: a molecular motor. Science (1993) 261:50-8. doi:10.1126/science.8316857

26. Krendel M, Mooseker MS. Myosins: tails (and heads) of functional diversity. Physiology (Bethesda) (2005) 20:239-51. doi:10.1152/physiol.00014.2005

27. Kim SV, Mehal WZ, Dong X, Heinrich V, Pypaert M, Mellman I, et al. Modulation of cell adhesion and motility in the immune system by Myolf. Science (2006) 314:136-9. doi:10.1126/science.1131920

28. Maravillas-Montero JL, Santos-Argumedo L. The myosin family: unconventional roles of actin-dependent molecular motors in immune cells. J Leukoc Biol (2012) 91:35-46. doi:10.1189/jlb.0711335

29. Santos-Argumedo L, Maravillas-Montero JL, Lopez-Ortega O. Class I myosins in B-cell physiology: functions in spreading, immune synapses, motility, and vesicular traffic. Immunol Rev (2013) 256:190-202. doi:10.1111/ imr.12105

30. Patino-Lopez G, Aravind L, Dong X, Kruhlak MJ, Ostap EM, Shaw S. Myosin $1 \mathrm{G}$ is an abundant class I myosin in lymphocytes whose localization at the plasma membrane depends on its ancient divergent pleckstrin homology (PH) domain (MyolPH). J Biol Chem (2010) 285:8675-86. doi:10.1074/ jbc.M109.086959

31. Dart AE, Tollis S, Bright MD, Frankel G, Endres RG. The motor protein myosin $1 \mathrm{G}$ functions in FcgammaR-mediated phagocytosis. J Cell Sci (2012) 125:6020-9. doi:10.1242/jcs.109561

32. Olety B, Walte M, Honnert U, Schillers H, Bahler M. Myosin 1G (Myo1G) is a haematopoietic specific myosin that localises to the plasma membrane and regulates cell elasticity. FEBS Lett (2010) 584:493-9. doi:10.1016/j. febslet.2009.11.096

33. Maravillas-Montero JL, Lopez-Ortega O, Patino-Lopez G, Santos-Argumedo L. Myosin 1g regulates cytoskeleton plasticity, cell migration, exocytosis, and endocytosis in B lymphocytes. Eur I Immunol (2014) 44:877-86. doi:10.1002/ eji.201343873

34. Linkermann A, Gelhaus C, Lettau M, Qian J, Kabelitz D, Janssen O. Identification of interaction partners for individual SH3 domains of Fas ligand associated members of the PCH protein family in T lymphocytes. Biochim Biophys Acta (2009) 1794:168-76. doi:10.1016/j.bbapap. 2008.10.013

35. Perez-Hernandez D, Gutierrez-Vazquez C, Jorge I, Lopez-Martin S, Ursa A, Sanchez-Madrid F, et al. The intracellular interactome of tetraspanin-enriched microdomains reveals their function as sorting machineries toward exosomes. J Biol Chem (2013) 288:11649-61. doi:10.1074/jbc. M112.445304

36. Buschow SI, van Balkom BW, Aalberts M, Heck AJ, Wauben M, Stoorvogel W. MHC class II-associated proteins in B-cell exosomes and potential functional implications for exosome biogenesis. Immunol Cell Biol (2010) 88:851-6. doi:10.1038/icb.2010.64

37. Santos-Argumedo L, Kincade PW, Partida-Sanchez S, Parkhouse RM. CD44-stimulated dendrite formation ('spreading') in activated B cells. Immunology (1997) 90:147-53. doi:10.1046/j.1365-2567.1997.00126.x

38. Perez-Montesinos G, Lopez-Ortega O, Piedra-Reyes J, Bonifaz LC, Moreno J. Dynamic changes in the intracellular association of selected rab small GTPases with MHC class II and DM during dendritic cell maturation. Front Immunol (2017) 8:340. doi:10.3389/fimmu.2017.00340

39. van Weert AW, Geuze HJ, Groothuis B, Stoorvogel W. Primaquine interferes with membrane recycling from endosomes to the plasma membrane through a direct interaction with endosomes which does not involve neutralisation of endosomal $\mathrm{pH}$ nor osmotic swelling of endosomes. Eur J Cell Biol (2000) 79:394-9. doi:10.1078/0171-9335-00062

40. Stein BS, Bensch KG, Sussman HH. Complete inhibition of transferrin recycling by monensin in K562 cells. J Biol Chem (1984) 259:14762-72.

41. Maravillas-Montero JL, Gillespie PG, Patino-Lopez G, Shaw S, SantosArgumedo L. Myosin 1c participates in B cell cytoskeleton rearrangements, is recruited to the immunologic synapse, and contributes to antigen presentation. J Immunol (2011) 187:3053-63. doi:10.4049/jimmunol. 1004018

42. Schnoor M, Lai FP, Zarbock A, Klaver R, Polaschegg C, Schulte D, et al. Cortactin deficiency is associated with reduced neutrophil recruitment but increased vascular permeability in vivo. J Exp Med (2011) 208:1721-35. doi:10.1084/jem. 20101920

43. Vachon E, Martin R, Plumb J, Kwok V, Vandivier RW, Glogauer M, et al. CD44 is a phagocytic receptor. Blood (2006) 107:4149-58. doi:10.1182/ blood-2005-09-3808

44. Lopez-Ortega O, Ovalle-Garcia E, Ortega-Blake I, Antillon A, ChavezMunguia B, Patino-Lopez G, et al. Myolg is an active player in maintaining cell stiffness in B-lymphocytes. Cytoskeleton (Hoboken) (2016) 73:258-68. doi: $10.1002 / \mathrm{cm} .21299$

45. Sumoza-Toledo A, Santos-Argumedo L. The spreading of B lymphocytes induced by $\mathrm{CD} 44$ cross-linking requires actin, tubulin, and vimentin rearrangements. J Leukoc Biol (2004) 75:233-9. doi:10.1189/jlb.0803403

46. Greicius G, Westerberg L, Davey EJ, Buentke E, Scheynius A, Thyberg J, et al. Microvilli structures on B lymphocytes: inducible functional domains? Int Immunol (2004) 16:353-64. doi:10.1093/intimm/dxh031

47. Hagiwara H, Kogure SY, Nakamura M, Shimada Y, Ohno-Iwashita Y, Fujimoto T. Cross-linking of plasmalemmal cholesterol in lymphocytes induces capping, membrane shedding, and endocytosis through coated pits. Biochem Biophys Res Commun (1999) 260:516-21. doi:10.1006/bbrc.1999.0879

48. Goding JW, Layton JE. Antigen-induced co-capping of IgM and IgD-like receptors on murine B cells. J Exp Med (1976) 144:852-7. doi:10.1084/ jem.144.3.852

49. Jugloff LS, Jongstra-Bilen J. Cross-linking of the IgM receptor induces rapid translocation of IgM-associated Ig alpha, Lyn, and Syk tyrosine kinases to the membrane skeleton. J Immunol (1997) 159:1096-106.

50. Nossal GJ, Layton JE. Antigen-induced aggregation and modulation of receptors on hapten-specific B lymphocytes. J Exp Med (1976) 143:511-28. doi:10.1084/jem.143.3.511

51. Raff MC, Feldmann M, De Petris S. Monospecificity of bone marrowderived lymphocytes. J Exp Med (1973) 137:1024-30. doi:10.1084/jem. 137.4.1024

52. Shimo K, Gyotoku Y, Arimitsu Y, Kakiuchi T, Mizuguchi J. Participation of tyrosine kinase in capping, internalization, and antigen presentation through membrane immunoglobulin in BAL17 B lymphoma cells. FEBS Lett (1993) 323:171-4. doi:10.1016/0014-5793(93)81473-D

53. Tsokos GC, Thyphronitis G, Jack RM, Finkelman FD. Ligand-loaded but not free complement receptors for $\mathrm{C} 3 \mathrm{~b} / \mathrm{C} 4 \mathrm{~b}$ and $\mathrm{C} 3 \mathrm{~d}$ co-cap with crosslinked B cell surface IgM and IgD. J Immunol (1988) 141:1261-6.

54. Bourguignon LY, Lokeshwar VB, Chen X, Kerrick WG. Hyaluronic acidinduced lymphocyte signal transduction and HA receptor (GP85/CD44)cytoskeleton interaction. J Immunol (1993) 151:6634-44.

55. Foger N, Marhaba R, Zoller M. CD44 supports T cell proliferation and apoptosis by apposition of protein kinases. Eur J Immunol (2000) 30: 2888-99. doi:10.1002/1521-4141(200010)30:10<2888::AID-IMMU2888> 3.0.CO; $2-4$ 
56. Lee JH, Katakai T, Hara T, Gonda H, Sugai M, Shimizu A. Roles of p-ERM and Rho-ROCK signaling in lymphocyte polarity and uropod formation. J Cell Biol (2004) 167:327-37. doi:10.1083/jcb.200403091

57. Martinelli S, Chen EJ, Clarke F, Lyck R, Affentranger S, Burkhardt JK, et al. Ezrin/Radixin/Moesin proteins and flotillins cooperate to promote uropod formation in T cells. Front Immunol (2013) 4:84. doi:10.3389/ fimmu.2013.00084

58. Jing J, Tarbutton E, Wilson G, Prekeris R. Rab11-FIP3 is a Rab11binding protein that regulates breast cancer cell motility by modulating the actin cytoskeleton. Eur J Cell Biol (2009) 88:325-41. doi:10.1016/j. ejcb.2009.02.186

59. Nabi IR. The polarization of the motile cell. J Cell Sci (1999) 112(Pt 12): 1803-11.

60. Thapa N, Anderson RA. PIP2 signaling, an integrator of cell polarity and vesicle trafficking in directionally migrating cells. Cell Adh Migr (2012) 6:409-12. doi:10.4161/cam.21192

61. White DP, Caswell PT, Norman JC. alpha v beta3 and alpha5betal integrin recycling pathways dictate downstream Rho kinase signaling to regulate persistent cell migration. J Cell Biol (2007) 177:515-25. doi:10.1083/ jcb.200609004

62. Hiebsch RR, Raub TJ, Wattenberg BW. Primaquine blocks transport by inhibiting the formation of functional transport vesicles. Studies in a cell-free assay of protein transport through the Golgi apparatus. J Biol Chem (1991) 266:20323-8.

63. Kaiser J, Stockert RJ, Wolkoff AW. Effect of monensin on receptor recycling during continuous endocytosis of asialoorosomucoid. Exp Cell Res (1988) 174:472-80. doi:10.1016/0014-4827(88)90316-3

64. Manna PT, Smith AJ, Taneja TK, Howell GJ, Lippiat JD, Sivaprasadarao A. Constitutive endocytic recycling and protein kinase C-mediated lysosomal degradation control K(ATP) channel surface density. J Biol Chem (2010) 285:5963-73. doi:10.1074/jbc.M109.066902

65. Pathak SS, Blum JS. Endocytic recycling is required for the presentation of an exogenous peptide via MHC class II molecules. Traffic (2000) 1:561-9. doi:10.1034/j.1600-0854.2000.010706.x

66. Schwartz AL, Bolognesi A, Fridovich SE. Recycling of the asialoglycoprotein receptor and the effect of lysosomotropic amines in hepatoma cells. J Cell Biol (1984) 98:732-8. doi:10.1083/jcb.98.2.732

67. Wileman T, Boshans RL, Schlesinger P, Stahl P. Monensin inhibits recycling of macrophage mannose-glycoprotein receptors and ligand delivery to lysosomes. Biochem J (1984) 220:665-75. doi:10.1042/bj2200665

68. Desplanques AS, Nauwynck HJ, Tilleman K, Deforce D, Favoreel HW. Tyrosine phosphorylation and lipid raft association of pseudorabies virus glycoprotein E during antibody-mediated capping. Virology (2007) 362:60-6. doi:10.1016/j.virol.2006.12.018

69. Gupta N, DeFranco AL. Visualizing lipid raft dynamics and early signaling events during antigen receptor-mediated B-lymphocyte activation. Mol Biol Cell (2003) 14:432-44. doi:10.1091/mbc.02-05-0078

70. Leitinger B, Hogg N. The involvement of lipid rafts in the regulation of integrin function. J Cell Sci (2002) 115:963-72.

71. Stuermer CA, Langhorst MF, Wiechers MF, Legler DF, Von Hanwehr SH, Guse AH, et al. PrPc capping in T cells promotes its association with the lipid raft proteins reggie-1 and reggie-2 and leads to signal transduction. FASEB J (2004):1731-3. doi:10.1096/fj.04-2150fje

72. Caliceti C, Zambonin L, Rizzo B, Fiorentini D, Vieceli Dalla Sega F, Hrelia S, et al. Role of plasma membrane caveolae/lipid rafts in VEGF-induced redox signaling in human leukemia cells. Biomed Res Int (2014) 2014:857504. doi:10.1155/2014/857504

73. Donatello S, Babina IS, Hazelwood LD, Hill AD, Nabi IR, Hopkins AM. Lipid raft association restricts CD44-ezrin interaction and promotion of breast cancer cell migration. Am J Pathol (2012) 181:2172-87. doi:10.1016/j. ajpath.2012.08.025

74. Feng X, Huang H, Yang Y, Frohlich O, Klein JD, Sands JM, et al. Caveolin-1 directly interacts with UT-A1 urea transporter: the role of caveolae/lipid rafts in UT-A1 regulation at the cell membrane. Am J Physiol Renal Physiol (2009) 296:F1514-20. doi:10.1152/ajprenal.00068.2009

75. Norambuena A, Schwartz MA. Effects of integrin-mediated cell adhesion on plasma membrane lipid raft components and signaling. Mol Biol Cell (2011) 22:3456-64. doi:10.1091/mbc.E11-04-0361
76. Rhee HJ, Ji L, Kim SH, Lee J. Human group V secretory phospholipase A2 is associated with lipid rafts and internalized in a flotillindependent pathway. Int J Mol Med (2013) 32:1126-36. doi:10.3892/ijmm.2013.1492

77. Kim J, London E. Using sterol substitution to probe the role of membrane domains in membrane functions. Lipids (2015) 50:721-34. doi:10.1007/ s11745-015-4007-y

78. Lingwood D, Simons K. Lipid rafts as a membrane-organizing principle. Science (2010) 327:46-50. doi:10.1126/science.1174621

79. Ramprasad OG, Srinivas G, Rao KS, Joshi P, Thiery JP, Dufour S, et al. Changes in cholesterol levels in the plasma membrane modulate cell signaling and regulate cell adhesion and migration on fibronectin. Cell Motil Cytoskeleton (2007) 64:199-216. doi:10.1002/cm.20176

80. Li XC, Zhuo JL. Selective knockdown of AT1 receptors by RNA interference inhibits Val5-ANG II endocytosis and NHE-3 expression in immortalized rabbit proximal tubule cells. Am J Physiol Cell Physiol (2007) 293:C367-78. doi:10.1152/ajpcell.00463.2006

81. Piasek A, Thyberg J. Effects of colchicine on endocytosis and cellular inactivation of horseradish peroxidase in cultured chondrocytes. J Cell Biol (1979) 81:426-37. doi:10.1083/jcb.81.2.426

82. Punnonen EL, Ryhanen K, Marjomaki VS. At reduced temperature, endocytic membrane traffic is blocked in multivesicular carrier endosomes in rat cardiac myocytes. Eur J Cell Biol (1998) 75:344-52. doi:10.1016/ S0171-9335(98)80067-8

83. Tomoda H, Kishimoto Y, Lee YC. Temperature effect on endocytosis and exocytosis by rabbit alveolar macrophages. J Biol Chem (1989) 264: 15445-50.

84. Chaudhary N, Gomez GA, Howes MT, Lo HP, McMahon KA, Rae JA, et al. Endocytic crosstalk: cavins, caveolins, and caveolae regulate clathrin-independent endocytosis. PLoS Biol (2014) 12:e1001832. doi:10.1371/journal. pbio. 1001832

85. Brandstaetter H, Kendrick-Jones J, Buss F. Myolc regulates lipid raft recycling to control cell spreading, migration and Salmonella invasion. J Cell Sci (2012) 125:1991-2003. doi:10.1242/jcs.097212

86. Maldonado-Baez L, Cole NB, Kramer H, Donaldson JG. Microtubuledependent endosomal sorting of clathrin-independent cargo by Hook1. J Cell Biol (2013) 201:233-47. doi:10.1083/jcb.201208172

87. Negulescu PA, Krasieva TB, Khan A, Kerschbaum HH, Cahalan MD. Polarity of T cell shape, motility, and sensitivity to antigen. Immunity (1996) 4:421-30. doi:10.1016/S1074-7613(00)80409-4

88. Marhaba R, Zoller M. CD44 in cancer progression: adhesion, migration and growth regulation. J Mol Histol (2004) 35:211-31. doi:10.1023/B:HIJO. 0000032354.94213 .69

89. Ponta H, Sherman L, Herrlich PA. CD44: from adhesion molecules to signalling regulators. Nat Rev Mol Cell Biol (2003) 4:33-45. doi:10.1038/ nrm1004

90. Chen XW, Leto D, Chiang SH, Wang Q, Saltiel AR. Activation of RalA is required for insulin-stimulated Glut4 trafficking to the plasma membrane via the exocyst and the motor protein Myolc. Dev Cell (2007) 13:391-404. doi:10.1016/j.devcel.2007.07.007

91. Tiwari A, Jung JJ, Inamdar SM, Nihalani D, Choudhury A. The myosin motor Myo1c is required for VEGFR2 delivery to the cell surface and for angiogenic signaling. Am J Physiol Heart Circ Physiol (2013) 304:H687-96. doi:10.1152/ ajpheart.00744.2012

92. Hegde VL, Singh NP, Nagarkatti PS, Nagarkatti M. CD44 mobilization in allogeneic dendritic cell-T cell immunological synapse plays a key role in T cell activation. J Leukoc Biol (2008) 84:134-42. doi:10.1189/jlb.1107752

93. Oliferenko S, Paiha K, Harder T, Gerke V, Schwarzler C, Schwarz H, et al. Analysis of CD44-containing lipid rafts: recruitment of annexin II and stabilization by the actin cytoskeleton. J Cell Biol (1999) 146:843-54. doi:10.1083/ jcb.146.4.843

94. Patel HH, Insel PA. Lipid rafts and caveolae and their role in compartmentation of redox signaling. Antioxid Redox Signal (2009) 11:1357-72. doi:10.1089/ARS.2008.2365

95. Lee JL, Wang MJ, Sudhir PR, Chen JY. CD44 engagement promotes matrix-derived survival through the CD44-SRC-integrin axis in lipid rafts. Mol Cell Biol (2008) 28:5710-23. doi:10.1128/MCB.00186-08

96. Murai T. The role of lipid rafts in cancer cell adhesion and migration. Int J Cell Biol (2012) 2012:763283. doi:10.1155/2012/763283 
97. Balasubramanian N, Scott DW, Castle JD, Casanova JE, Schwartz MA. Arf6 and microtubules in adhesion-dependent trafficking of lipid rafts. Nat Cell Biol (2007) 9:1381-91. doi:10.1038/ncb1657

98. Saeki K, Miura Y, Aki D, Kurosaki T, Yoshimura A. The B cell-specific major raft protein, Raftlin, is necessary for the integrity of lipid raft and BCR signal transduction. EMBO J (2003) 22:3015-26. doi:10.1093/emboj/ $\operatorname{cdg} 293$

99. Asano S, Kitatani K, Taniguchi M, Hashimoto M, Zama K, Mitsutake S, et al. Regulation of cell migration by sphingomyelin synthases: sphingomyelin in lipid rafts decreases responsiveness to signaling by the CXCL12/ CXCR4 pathway. Mol Cell Biol (2012) 32:3242-52. doi:10.1128/MCB. 00121-12

100. Schmidt C, Kim D, Ippolito GC, Naqvi HR, Probst L, Mathur S, et al. Signalling of the BCR is regulated by a lipid rafts-localised transcription factor, Bright. EMBO J (2009) 28:711-24. doi:10.1038/emboj.2009.20

101. Uhlin M, Masucci MG, Levitsky V. Pharmacological disintegration of lipid rafts decreases specific tetramer binding and disrupts the CD3 complex and CD8 heterodimer in human cytotoxic T lymphocytes. Scand J Immunol (2003) 57:99-106. doi:10.1046/j.1365-3083.2003.01188.x

102. Trujillo MA, Jiang SW, Tarara JE, Eberhardt NL. Clustering of the B cell receptor is not required for the apoptotic response. DNA Cell Biol (2003) 22:513-23. doi:10.1089/10445490360708928

103. Guo S, Bao S. srGAP2 arginine methylation regulates cell migration and cell spreading through promoting dimerization. J Biol Chem (2010) 285:35133-41. doi:10.1074/jbc.M110.153429
104. Zhang X, Bi E, Novick P, Du L, Kozminski KG, Lipschutz JH, et al. Cdc42 interacts with the exocyst and regulates polarized secretion. J Biol Chem (2001) 276:46745-50. doi:10.1074/jbc.M107464200

105. Mason FM, Heimsath EG, Higgs HN, Soderling SH. Bi-modal regulation of a formin by srGAP2. J Biol Chem (2011) 286:6577-86. doi:10.1074/jbc. M110.190397

106. Cairns AP, Crockard AD, Bell AL. CD36-mediated apoptotic cell clearance in SLE. Lupus (2001) 10:656-7. doi:10.1191/096120301682430276

107. Acharya PS, Majumdar S, Jacob M, Hayden J, Mrass P, Weninger W, et al. Fibroblast migration is mediated by CD44-dependent TGF beta activation. J Cell Sci (2008) 121:1393-402. doi:10.1242/jcs.021683

108. Zoller M, Gupta P, Marhaba R, Vitacolonna M, Freyschmidt-Paul P. Anti-CD44-mediated blockade of leukocyte migration in skin-associated immune diseases. J Leukoc Biol (2007) 82:57-71. doi:10.1189/jlb.0107063

Conflict of Interest Statement: The authors declare that the research was conducted in the absence of any commercial or financial relationships that could be construed as a potential conflict of interest.

Copyright $\odot 2017$ López-Ortega and Santos-Argumedo. This is an open-access article distributed under the terms of the Creative Commons Attribution License (CC BY). The use, distribution or reproduction in other forums is permitted, provided the original author(s) or licensor are credited and that the original publication in this journal is cited, in accordance with accepted academic practice. No use, distribution or reproduction is permitted which does not comply with these terms. 